\title{
Experimental and numerical investigations on glass fragments: shear-frame testing and calibration of Mohr-Coulomb plasticity model
}

\author{
Alexander Pauli $\mathbb{D}$ - Michael A. Kraus $\mathbb{D}$. \\ Geralt Siebert
}

Received: 15 May 2020 / Accepted: 20 November 2020 / Published online: 22 February 2021

(C) The Author(s) 2021

\begin{abstract}
The numerical treatment of the residual load-bearing behavior of laminated glasses (LG) in the post-fractured state is highly topical. Nevertheless, currently only few numerical approaches for an accurate representation of the experimentally observed behavior are existent. In order to model the characteristics of the load-bearing behavior of glass laminates in the post-fractured state, the behavior of the interlayer, the behavior of the glass fragments as well as the bonding between glass and interlayer need to be characterized correctly. This paper focuses on the modeling of the frictional contacts between the glass fragments itself. In order to allow for the calibration of failure criteria for the fractured glass particles, framed shear tests which are a common experimental technique in geomechanical testing to determine the shear strength of soils, are performed on glass fragments of different thicknesses and levels of thermal pre-stress. The test results are subsequently used to calibrate nonassociated Mohr-Coulomb criteria, which are widely applied to the description of failure and frictional sliding of soils, to the experimental data of four distinct kinds of glass fragments. The obtained parameters of
\end{abstract}

\footnotetext{
A. Pauli $(\varangle) \cdot$ G. Siebert

Bundeswehr University Munich, Werner-Heisenberg-Weg

39, 85579 Neubiberg, Germany

e-mail: alexander.pauli@unibw.de
}

M. A. Kraus ( $\square)$

Stanford University, Y2E2,473 Via Ortega, Stanford, CA

94305, USA

e-mail:makraus@stanford.edu the Mohr-Coulomb models are in magnitude similar to the parameters of standard soils such as sand or gravel. The experimental data further show, that the Mohr-Coulomb model in general can be used to approximate the stress failure plane of the glass fragments but lacks for capturing correctly the plastic volumetric strains (dilation) in Finite Element modelling. Numerical investigations by the Finite Element method showed, that it is possible to reproduce experimental data by using Mohr-Coulomb plasticity models and hence the numerical models are validated for further investigations.

Keywords Post-fractured state - Glass fragments · Geomechanical testing

\section{Introduction}

Nowadays glass is one of the most popular building materials due to its inherent transparency and aesthetic design possibility. Therefore, the requirement for the residual load-bearing capacity of glass structures is also highly topical. According to the "fail safe approach" (Feldmann et al. 2014) in structural glass engineering, in case of partial or total fragmentation of glass, the glass structure has to provide sufficient stiffness and strength, delivering a certain post-fracture performance under at least the permanent loads as well as a fraction of the live loads. As glass alone in the fractured state is not able to meet this requirement, at least 
two sheets of glass are laminated together with a polymeric interlayer to form laminated glass (LG). If further requirements such as certain load-carrying behavior, the maximum size of the glass fracture particles or the glass shards remaining attached to the polymer, are met, LGs are classified laminated safety glass (LSG). The fracture pattern of moderately to highly pre-stressed glasses is very fine in scale and the shape of the particles strongly depends on the actual level of pre-stress and thickness of the glass (Kraus 2019; Pour-Moghaddam 2020, 2019). However, as the shape and strength of the glass fragments are reminiscent of sharp-edged gravel (Smoltczyk 2001), it can be assumed that they also act accordingly and thus established constitutive laws from geotechnical engineering look promising for a computational mechanical modelling approach. The goal within this paper therefore is to characterize the behavior of the glass fragments by means of geomechanical experiments and constitutive models for further numerical treatment.

The contributions of this paper are fourfold: (1) the modelling of fractured glass laminates is briefly elaborated for distinct numerical treatment frameworks (2) it is suggested to use plasticity models for the incorporation of the contribution of the glass fragments in further numerical analysis of fractured glass laminates (3) conduction and reporting of experiments on several fractured glass pane specimen and calibration of nonassociated Mohr-Coulomb material models (4) validation of Finite Element models against the experiments.

The rest of this paper is organized as follows: in Sect. 2 the state of the art as well as the description of two frameworks for the numerical treatment of fractured glass laminates and modelling strategies are given. In Sect. 3 background information on the mechanical constitutive modelling of plasticity as well as failure criteria for geotechnical materials are recapitulated and the modelling constraints are discussed. In Sect. 4 the conduction of experiments on glass fragments of glass panes with different thicknesses and levels of pre-stress is described and the test results are reported. A further analysis of the obtained data is conducted and the calibration of the parameters of nonassociated Mohr-Coulomb models for the test specimen is carried out. In Sect. 5 the validation of Finite Element models against the experiments is conducted and reported. Further conclusions as well as an outlook are given in Sect. 6.

\section{Post-fracture load bearing capacity of glass laminates}

\subsection{State-of-the-art}

The load-carrying behavior of intact laminated glass has been studied extensively from the theoretical (Hooper 1973; Asik and Tezcan 2005; Ivanov 2006; Foraboschi 2009; Galuppi and Royer-Carfagni 2012; Aenlle et al. 2015), experimental (Behr et al. 1985, 1993), and numerical (Fröling and Persson 2013; Fröling et al. 2014; Mantari and Canales 2016; Jaśkowiec et al. 2017) point of view.

On the other hand, the modelling of the postfracture response of laminated glass still represents an open issue. Currently there exist several approaches to mechanically describe and experimentally capture either the global load-bearing behavior of glass laminates in the post-fractured state or local effects or components thereof. A number of investigations and experimental activities have been conducted on fractured laminated glass: in Fahlbusch (2008), a global stiffness of the fractured glass laminates is determined using tensile creep tests, in Kott and Vogel (2006) and Feirabend (2010) the yield-line theory is proposed, which initially was derived in Johansen (1962) for biaxially stressed reinforced concrete slabs. Fractured laminated glass was experimentally investigated under inplane (Biolzi et al. 2010, 2016; Speranzini and Agnetti 2014; Belis et al. 2009) and out-of-plane (Feirabend and Sobek 2008; Castori and Speranzini 2017) bending. Numerical simulations on fractured glass laminates are recorded in Timmel et al. (2007), Baraldi et al. (2016), Pelfrene (2016), Pelfrene et al. (2015) and Chen et al. (2017). In Seshadri (2001) and Franz (2015) a cohesive zone model is presented which considers the adhesion between glass and interlayer. In Kraus et al. (2019) and Kraus (2019) a machine learning based prediction algorithm is presented which enables to generate glass fracture patterns at low numerical effort for thermally pre-stressed glass in dependence of the thickness and pre-stress level of the glass pane. The implementation of the fractured glass laminates in a Finite Element Method code is numerically demanding due to the large amount of degrees of freedom. Analytical approaches are considered in Kott and Vogel (2004), Galuppi and Royer-Carfagni (2017), D’Ambrosio et al. (2019) and Galuppi and Royer-Carfagni (2018). 
A first methodical review and evaluation of different modelling strategies for glass laminates in the postfractured state is only given in Teotia and Soni (2018) and Vedrtnam and Pawar (2017), yet. Hence the next section of the paper will briefly highlight two potential modelling strategies for fractured glass laminates and specify the necessary material parameters and corresponding experiments.

\subsection{Modelling}

For the numerical treatment of post-fractured glass laminates three components have to be specified by appropriate mechanical models: fractured glass (green box), polymeric interlayer (blue box) and adhesion of glass particles to the interlayer (orange box), cf. Fig. 1. In general, two distinct modelling choices for the fractured glass laminate are now possible:

1. explicit modelling of the glass particles, their adhesion to the interlayer and the modelling of the interlayer behavior

2. homogenized approach, where the fractured glass and the interlayer are not modelled explicitly but the whole fractured glass laminate.

Both modelling variants differ in experimental and numerical complexity. From experiments it is however observed, that the fractured glass laminate shows two effects: on the one hand, the fracture creates many contact surfaces between the individual glass fragments, which interlock with each other, resulting in a steep increase in stiffness in the range of small and moderately large strains compared to the behavior of the interlayer only. Secondly, the glass laminate response is stiffened by the adhesion of the interlayer to the glass fragments (cf. Botz et al. 2019; Galuppi and RoyerCarfagni 2016) and the transverse strain restraint. The larger the deformation caused strains become, the more the interlayer delaminates from the glass fragments (cf. Pelfrene et al. 2015), which causes the stiffness to decrease again: under very large deformations, almost no glass fragments adhere to the interlayer and nonlinear viscoelastic material laws are required for the constitutive modelling of stress-strain-time phenomena.

As the contact behavior of the fractured glass particles is an important component of the load-bearing of fractured glass laminates and as the glass fragments are reminiscent of sharp-edged gravel, this paper investigates for the first time the idea of characterizing the glass fragments from panes with different thicknesses and levels of pre-stress via experiments used to mechanically characterize soils and sub sequentially calibrated models of plasticity. Usually information on the level of pre-stress associated with the respective fracture particles is recorded rarely when testing glass, hence the experimental and their investigation is of great value due to the data exclusivity. In the scope of this work, geotechnical investigations are used to characterize the mechanical material behavior of distinct glass fragments in order to allow the calibration of further material models of the glass fracture particles.

In the state of completely fractured glass of the laminate (state III), cf. Fig. 1, the verification of the loadbearing capacity so far can only be carried out by means of tests as there hardly exist reliable and realistic numerical procedures. With a numerical model being able to capture the complex mechanical behavior of fractured laminated glass it would be much more cost-effective and time-saving to investigate and analyze the residual load-bearing capacity of certain glass laminates together with their boundary conditions. Hence it is of great practical and theoretical interest to investigate modelling strategies of fractured glass laminates and

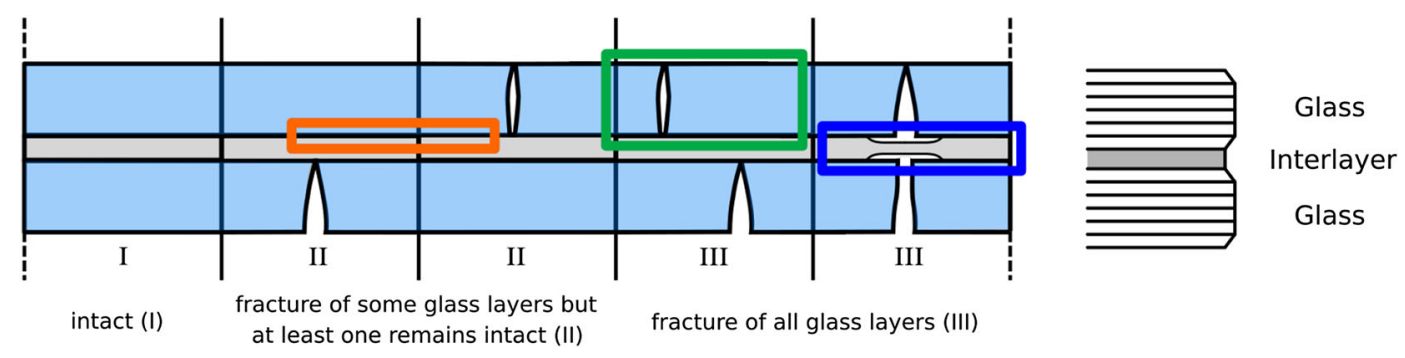

Fig. 1 Mechanical model for the load carrying in the intact (I) and fractured states (II, III), characterized by the behaviour of fractured glass (green box), polymeric interlayer (blue box) and adhesion of glass particles to the interlayer (orange box), Kraus (2019) 
the respective components from a theoretical as well as an experimental point of view.

\section{Characterization and modelling of granular media: lessons from numerical methods in geotechnical material modelling}

Given the inspiration of using geomechanical experiments for characterizing mechanical properties and material behavior of fractured glass particles, a natural consequence is using established numerical processes and methods from geomechanics for analyzing soil in the limit states. The finite element method (FEM) is widely used in engineering and hence in modelling of geotechnical problems in order to gain insight into how stresses and strains distribute within the soil. To enable these investigations, constitutive models are required, which are calibrated by test data from the laboratory. The behavior of soils may be modelled at different accuracy levels, typically for the case of the stress-strain relationship. Similarly to the proposed two modelling approaches of fractured glass laminates in Sect. 2.2, in geomechanics several homogenized or explicit constitutive models are known.

The experimental investigations of this paper in Sect. 4 serve as data basis for both, modelling strategies for quantifying the contributions of the glass particles to respective numerical approaches and the extraction of relevant phenomena to be captured by the material models. This subsection however is concerned with the particular material modelling choices for the fractured glass phase within the Finite Element Method. In the remainder of this section, at first the general setting of numerical treatment of plasticity is briefly recaptured, the material modelling approaches for 'perfectly plastic' and subsequently the approaches for 'plasticity with hardening/softening' are introduced and set into context with the experiments of this paper. Further material modelling strategies for the fractured glass laminate are outside the scope of this paper and will be treated in future papers of the authors given the database presented here. The concrete validation of a Finite Element model for numerically assessing the experiments of this paper is described together with the results in detail in Sect. 5.
3.1 Background on the numerical plasticity setting

In case of large enough deformations, a linear stressstrain relation is no longer justifiable to correctly model the material behavior, for geotechnical materials then linear elastic-perfectly plastic constitutive laws are commonly applied (Senseny et al. 1983). Therefore the development of critical state constitutive models has provided a major advance in the use of plasticity theory in geomechanics. A relatively simple model using an associated flow rule is able to predict, at least qualitatively, a great number of the fundamental aspects of soil behavior (Möller 2013; Smoltczyk 2001; Das and Sivakugan 2016; Holtz et al. 1981). Plasticity models for frictional materials such as concrete, soil and rock are most conveniently represented in the principal stress space (Möller 2013; Borja et al. 2003; Lang et al. 2010; Dunne and Petrinic 2005; Das and Sivakugan 2016). Using the mean value of the stress on the main diagonal $\sigma_{m}=\left(\sigma_{11}+\sigma_{22}+\sigma_{33}\right) / 3=\frac{\sigma_{k k}}{3}$ the stress tensor $\sigma_{i j}$ can be divided into a hydrostatic and a deviatoric part (Katzenbach 2013; Smoltczyk 2001). In the following the Einstein summation convention is used, where $\mathrm{i}, \mathrm{j}=1,2,3$ :

$\sigma_{i j}=\frac{\sigma_{k k}}{3} \delta_{i j}+s_{i j}$

where $\frac{\sigma_{k k}}{3} \delta_{i j}$ presents the hydrostatic (spherical) and $s_{i j}$ the deviatoric part of the stress tensor. Flow surfaces in general are expressed with respect to the hydrostatic axis and the deviatoric plane, depicted in the principal stress space. Therefore each stress state can be expressed in cylindrical coordinates within the principal stress space. The axial distance along the hydrostatic axis is presented by $\xi$, the azimuth is present by the Lode angle $\Theta$, and the distance within the deviatoric plane is presented by $\rho$ (cf. Jeltsch-Fricker and Meckbach 1999; Müllerschön 2000; He et al. 2018; Bigoni and Piccolroaz 2004):

$$
\begin{aligned}
& \xi=\frac{\sqrt{3}}{3}\left(\sigma_{1}+\sigma_{2}+\sigma_{3}\right)=\frac{\sqrt{3}}{3} I_{1} \\
& \rho=\sqrt{s_{1}^{2}+s_{2}^{2}+s_{3}^{2}}=\sqrt{2 J_{2}} \\
& \Theta=\frac{1}{3} \cos ^{-1}\left(\frac{3 \sqrt{3}}{2} \frac{J_{3}}{J_{2}^{3 / 2}}\right)
\end{aligned}
$$




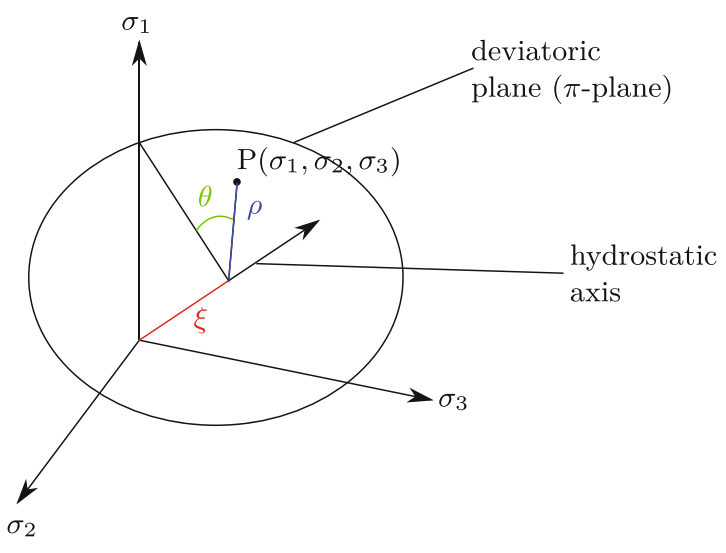

Fig. 2 Principal stress space representation

where $I_{1}$ equals the first invariant of the stress tensor and $J_{1}, J_{2}$ equal the first and second invariant of the deviatoric part of the stress tensor. However the general characteristics of the yield surface are described by its shape on the deviatoric plane ( $\pi$-plane) and its trace on the meridian plane (spanned by $\xi$ and $\rho$, while $\theta$ is constant) (cf. Fig. 2).

Coming back to the context of plasticity, a point in principal stress space shows elastic behavior as long as it is within the flow surface, which is limited by a certain flow rule. In other words, the surface in deviatoric stress space depicts the elastic domain with its limit characterized by the flow rule.

In frictional materials the form of the failure envelope is significantly affected by the value of the confining pressure. While the 'perfectly plastic' approaches are able to describe general soil behavior, necessary refinements for more accurate capturing of the mechanical material behavior is reached through introducing hardening and/or softening plasticity.

\subsubsection{Introduction of a failure criterion}

To formulate an elasto-plastic constitutive model, the following three essential ingredients are required (Möller 2013; Smoltczyk 2001; Holtz et al. 1981; Dunne and Petrinic 2005):

- Yield function First of all a specific yield-function needs to be defined, which for all kinds of stress states relates the single stress entries of the stress tensor with each other. If that function reaches zero, the respective material shows plastic behaviour. In the scope of this work only linear elastic ideal plas- tic material behaviour is considered, hence the flow function only depends on the respective stresses and is scalar valued.

$F(\sigma)=0$

- Flow rule As the flow function tends to zero, plastic behaviour occurs. From that point on the strains are separated into elastic and plastic components:

$\varepsilon_{i j}=\varepsilon_{i j}^{e}+\varepsilon_{i j}^{p}$

where $\varepsilon_{i j}^{e}$ denotes the elastic (reversible) and $\varepsilon_{i j}^{p}$ the plastic (irreversible) deformation. At this point it has to be noted, that this separation of the strain only holds for small deformations. Since there is no more clear connection between stresses and deformations in the state of plasticity and also the state of deformation depends on the stress history, rate equations or infinitesimal incremental relations are required. The behaviour of the material is assumed to not be time dependent and numerical solutions are mostly based on incremental formulations. Therefore, an infinitesimal incremental formulation is chosen in the following rather than a rate equation:

$d \varepsilon_{i j}=d \varepsilon_{i j}^{e}+d \varepsilon_{i j}^{p}$

where $d \varepsilon_{i j}^{e}$ denotes the infinitesimal incremental elastic (reversible) and $d \varepsilon_{i j}^{p}$ the infinitesimal incremental plastic (irreversible) deformation. The infinitesimal incremental plastic deformation is characterized by the flow rule. Furthermore, two kinds of flow rules can be distinguished:

1. Associated flow rule: for the associated rule the vector of the plastic deformation is considered normal to a convex yield surface. Therefore, the principal directions of accumulated stress and incremental plastic strain are enforced to coincide. A yield function, F, is defined, which is a scalar function of stress (expressed in terms of either the stress components or stress invariants) and state parameters:

$d \varepsilon_{i j}^{p}=d \lambda \frac{\partial F}{\partial \sigma_{i j}}$ 
Hence the stress gradient $\frac{\partial F}{\partial \sigma_{i j}}$ of the yield surface determines the direction of the plastic deformation $d \varepsilon_{i j}^{p}$ and the scalar factor $d \lambda$ determines its amount. Furthermore, dilatancy is determined by the mean stress dependence of the strength. It is known from Miller and Cheatham (1972), that an associated flow rule overestimates the dilatancy for deviatoric stress states. Therefore, for an accurate prediction a non-associated plastic flow rule is required.

2. Non-associated flow rule: in general, to receive a better coincidence between test results and model, there also can be applied a non-associated flow rule. Within the stress gradient $\frac{\partial F}{\partial \sigma_{i j}}$ the flow function is replaced by the plastic potential G. However, the flow surface as well as G has to be convex:

$$
d \varepsilon_{i j}^{p}=d \lambda \frac{\partial G}{\partial \sigma_{i j}}
$$

In contradiction to e.g. the Mohr-Coulomb model, which only considers elastic deformations within a hydrostatic load state, the cap model presented by Sandler et al. (1976) adds a cap to the flow surface in compressional direction of the hydrostatic stress axis. This model is often used for the inelastic behavior of rocks, if there is a remarkably plastic volume reduction under hydrostatic pressure.

However, as this work is a first try to capture the frictional behavior within glass fragments, in the following only a non-associated Mohr-Coulomb model is considered.

- Post failure hypothesis The post failure material behavior basically can be characterized by three types:

1. Linear elastic ideal plastic behavior: the yield criterion stays the same after the material is loaded and unloaded. The product of infinitesimal incremental stress and strain is equal to zero $(d \sigma: d \varepsilon=0)$ and the state of plasticity is therefore unstable.

2. Hardening behavior: the flow limit is increased if the material is loaded and unloaded. It can be split in isotropic hardening, where the plastic strain depends on a scalar value, and kinematic hardening, where the inner variable is expressed by the stress tensor (tensile and compressional loading). In general, the state is stable and the product of infinitesimal incremental stress and strain is greater than zero $(d \sigma: d \varepsilon>0)$.

3. Softening behavior: wihtin a softening behavior, the flow limit is reduced if the material is loaded and unloaded. The product of infinitesimal incremental stress and strain is lower than zero $(d \sigma: d \varepsilon<0)$ and therefore unstable.

For more detailed information regarding failure in general, the reader is referred to Altenbach (2012), Mang and Hofstetter (2000), Gurtin (1982), Spencer (2004) and Fung (1977).

\subsubsection{Perfectly plastic material models}

In geotechnical engineering the strength of a soil or granular medium in simple models is characterized by its shear-strength and many failure descriptions build up on this. A soil only shows a respective shear strength, if there are normal stresses, which activate the friction between the single particles of the soil. Plasticity based yield criteria commonly used to model geomaterials such as concrete, soils, rocks with distinctly different yield stresses in tension and compression can be found in Lang et al. (2010). Amongst others, the MohrCoulomb and Drucker-Prager model are well-known in both science and engineering practice as first attempts to describe constitutive behaviour of soil. For reasons of brevity, this paper will deduce material parameters just for the Mohr-Coulomb model. In the remainder of this paper, further analysis of the data allows calibration of more complex constitutive behaviors as well and thus make these data very valuable for the whole context of numerical modelling of fractured glass laminates. Nevertheless, it has to be mentioned, that the presence of corners within the Mohr-Coulomb model possesses certain difficulties to implementation and numerical treatment within a general three-dimensional framework, because differentiation on that corners is not possible. The Mohr-Coulomb model however can be transferred to the Drucker-Prager model, which possesses a smooth yield surface.

\subsection{Mohr-Coulomb criterion}

A classical plasticity model that considers the shape of the failure surface on the deviatoric plane is the MohrCoulomb model. Widely used for representing the yield 
Fig. 3 Mohr-Coulomb yield functions: a principal stress space representation; b deviatoric plane representation, Borja et al. (2003)

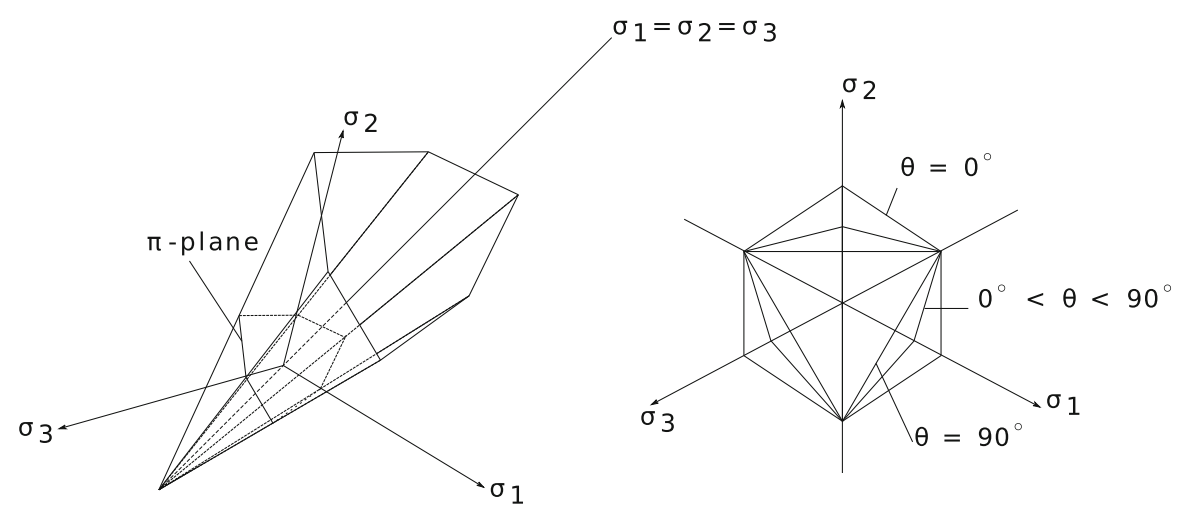

(a)

(b) and failure behavior of cohesive-frictional materials, this model has the shape of an irregular hexagon on the deviatoric plane and predicts a higher yield/failure strength in compression than in tension (Mang and Hofstetter 2000), cf. Fig. 3. In the following, several approaches regarding the Mohr-Coulomb failure criterion from literature are represented and requirements with respect to the numerical modelling are discussed. A general formulation of the elasto-plastic matrix for evaluating stress increments regarding the yield surface with an associated flow rule for a Coulomb type yield surfaces is presented for example in Zienkiewicz et al. (1969). In addition to Mohr-Coulomb yield criteria with linear or non-linear dependence of the Lode angle for which the non-smooth deviatoric trace is of major interest have been discussed by Bićanić et al. (1989) and De Borst (1987). Furthermore in Anand and Gu (2000) a three-dimensional elasto-plastic constitutive model for dry granular materials, based on the flow rule corresponding to the Mohr-Coulomb yield condition, is introduced and in Senseny et al. (1983) a hypoelastic, isotropically hardening plastic material formulation, based of the Mohr-Coulomb failure criterion is given for an associated as well as for a nonassociated flow rule in general.

As the Mohr-Coulomb is subject to further investigation, a more detailed explanation is given in the remainder of this section. Following Mohr (1900), Mohr-Coulomb is widely applied to the description of intact rock failure and to the description of rockon-rock frictional sliding (Byerlee 1978; Al-Ajmi and Zimmerman 2006; Rutter and Glover 2012). It plays also a decisive role in practice in order to estimate the far-field stresses from borehole breakout geometry (Vernik and Zoback 1992).
The Mohr-Coulomb yield surface is described by a cone with six edges, where the diameter increases in compression and decreases in tension, cf. Fig. 3. The friction angle $\varphi$ is the slope of the yield surface and the cohesion $c$ is the material strength under no additional confining normal stress, which is typically very small for soil materials. It is assumed that failure occurs at particular combinations of the largest and least principal stresses, without any influence of the principal stress in the third direction (Labuz and Zang 2012). According to Jaeger (2009) the Mohr-Coulomb criterion can be formulated either as a function of the principal stresses $\sigma_{1}$ and $\sigma_{3}\left(\sigma_{1}>\sigma_{2}>\sigma_{3}\right)$ or as a function of normal stress $\sigma$ and the respective shear stress $\tau$ on the failure plane.

The failure criterion of Mohr-Coulomb with respect to normal and shear stress yields, (cf. Fig. 4):

$\tau_{f}=c+\sigma_{f} \tan (\varphi)$

and with respect to principal stresses it is given according to Mang and Hofstetter (2000) by:

$\frac{\left(\sigma_{1}-\sigma_{3}\right)}{2}-\frac{\left(\sigma_{1}+\sigma_{3}\right)}{2} \sin (\varphi)=c \cos (\varphi)$

and after some rearrangements results in:

$\sigma_{1} \frac{1-\sin (\varphi)}{2 c \cos (\varphi)}-\sigma_{3} \frac{1+\sin (\varphi)}{2 c \cos (\varphi)}=1$

where $\sigma_{1}$ corresponds to the maximum and $\sigma_{3}$ to the minimum stress. If it is postulated that $\sigma_{1}=f_{c}$, where $f_{c}$ equals the maximum strength in compression, and $\sigma_{3}=0$ Eq. (12) is reduced to Mang and Hofstetter (2000): 


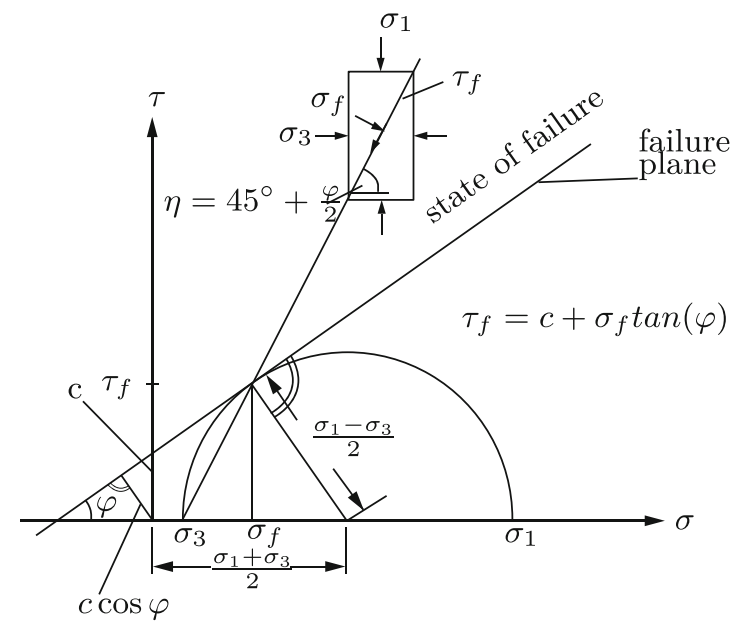

Fig. 4 Mohr's stress circle according to Mang and Hofstetter (2000), Lang et al. (2010) and Witt (2008)

$f_{c}=\frac{2 c \cdot \cos (\varphi)}{1-\sin (\varphi)}$

The maximum value of $\sigma_{3}$ has to be reduced to the maximum strength in tension $f_{t}$, because failure is characterized by a separation break and would be overestimated if it would be determined just from the framed shear test (Witt 2008).

If it is postulated, that $\sigma_{1}=0$ and $\sigma_{3}=-f_{t}$, failure is characterized by a shear fracture (Witt 2008) and Eq. (12) is reduced according to Mang and Hofstetter (2000):

$f_{t}=\frac{2 c \cdot \cos (\varphi)}{1+\sin (\varphi)}$

where within Eq. (14) the respective maximum strength in tension is determined and Eq. (13) yields the respective maximum strength in compression. If the angle of inner friction in Eq. (12) is set to zero and the cohesion is set to $\frac{f_{y}}{2}$, the Mohr-Coulomb flow condition reduces to the Tresca failure criterion (Mang and Hofstetter 2000).

A respective flow function as introduced in Sect. 3.1.1 can be derived from Eq. (10) with respect to shear $\tau_{f}$ and normal stress $\sigma_{f} . \tau_{f}$ and $\sigma_{f}$ present the stress state where the material starts to flow. This state is located on the outer surface of the cone, depicted in Fig. 3, which marks the so called flow surface:

$$
F\left(\sigma_{f}, \tau_{f}\right)=\tau_{f}-\sigma_{f} \tan (\varphi)-c
$$

Furthermore the flow function can also be expressed in terms of the largest and least principal stresses $\sigma_{1}$ and $\sigma_{3}:$

$$
F\left(\sigma_{1}, \sigma_{3}\right)=\frac{\left(\sigma_{1}-\sigma_{3}\right)}{2}-\left[\frac{\left(\sigma_{1}+\sigma_{3}\right)}{2} \sin (\varphi)+c \cos (\varphi)\right]
$$

As material models in general need to be independent from any basis, they need to be formulated in terms of invariants (Smoltczyk 2001):

$$
\begin{aligned}
F\left(I_{1}, J_{2}, J_{3}\right)= & -I_{1} \frac{\sin (\varphi)}{3} \\
& +\left(\cos \left(\frac{1}{3} \cos ^{-1}\left(\frac{3 \sqrt{3}}{2} \frac{J_{3}}{J_{2}^{3 / 2}}\right)\right)\right. \\
& \left.-\frac{\sin (\varphi) \sin \left(\frac{1}{3} \cos ^{-1}\left(\frac{3 \sqrt{3}}{2} \frac{J_{3}}{J_{2}^{3 / 2}}\right)\right)}{\sqrt{3}}\right) \\
& \sqrt{J_{2}}-c \cos (\varphi)
\end{aligned}
$$

where $I_{1}$ equals the first invariant of the stress tensor and $J_{2}$ and $J_{3}$ equal the second and third invariant of the deviatoric stress tensor. An analogous formulation is implemented in Ansys and used in Sect. 6 for the numerical modelling of the experiments.

\subsection{Mohr-Coulomb: finite element implementation}

The material which is subject of the further investigations within this paper is modelled as a non-associated linear elastic perfectly-plastic Mohr-Coulomb model, which implies four independent material parameters:

- Young's modulus $E$

- Poisson's ratio $v$ (analogously to linear elasticity)

- friction angle $\varphi$

- cohesion $c$.

Within the Finite Element Method (FEM), the Mohr-Coulomb hypothesis can either be modelled associated or non-associated. In the case of an associated modelling, the flow rule $F(\sigma)$ which depends on the stress is equivalent to the plastic potential function which shows the direction of plastic strain increment. With this approximation the material stiffness matrices 
and the global structural stiffness matrices are unsymmetric. This is an advantage because the calculation is time-saving. Furthermore, the material is modelled perfectly plastic, hence there is no hardening/softening law required. As already mentioned, the material modelling in the context of an Finite Elements Analysis is based on expressions in terms of invariants, which is shown in Fig. 3 for the case of the Mohr-Coulomb criterion (Witt 2008; Borja et al. 2003).

In the following sections it will be shown, that the obtained experimental data allow for a further calibration of a post-failure softening of the Mohr-Coulomb criterion, which will be investigated in Sect. 5. For reasons of brevity, the further recapitulation of the mechanical-numerical background on softening formulations for plasticity and failure criteria is omitted at this point. However a short introduction is given in Sect. 3.1.1.

\section{Experimental investigations}

In order to calibrate respective parameters for the Mohr-Coulomb failure criterion, basically two types of tests are carried out on glass fragments on glass panes with different but distinct thermal pre-stress levels. In a first step respective sieving curves are investigated, to check which size of the shear frame for the second test setup can be used. After obtaining these curves, shear tests with three different magnitudes of normal stress for each specimen are carried out. The glass fracture particles as well as the two tests and their respective set-up and evaluation are described in the subsequent sections.

\subsection{Glass specimen for fracture particle investigations}

The glass fragments under investigation were extracted from panes $(1100 \mathrm{~mm} \times 360 \mathrm{~mm})$ made of tempered soda-lime-silica glass and remained from prior investigations of Pour-Moghaddam (2019) with respect to the characterization of glass fracture particles for different levels of internal energy due to thermal tempering. It has to be mentioned, that the amount of pre-stress of these specimens is chosen to specific levels, which are below the normative minimum value for safety glass. This tempering was done on purpose to achieve different fracture patterns with distinct characteristics such

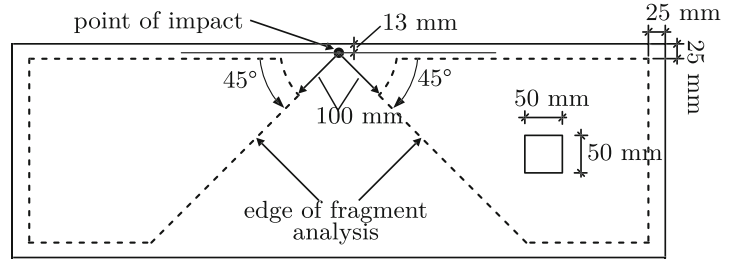

Fig. 5 Extraction of the glass fragments within dashed regions to exclude punch-induced artefacts in the glass fracture pattern, Pour-Moghaddam (2019)

as fracture particle sizes, cf. Kraus (2019) and PourMoghaddam (2019).

The panes were fractured by a center punch and the fragments within specific areas were collected and analyzed. From Kraus (2019) and Pour-Moghaddam (2019) it is known, that the level of pre-stress together with the thickness of the glass pane are correlated to characteristics of the fracture pattern, hence this study uses two different glass pane thicknesses and two levels of pre-stress. Figure 5 shows the respective areas of analysis, Table 1 shows the properties of the fragments of each specimen. There $\sigma_{s}$ is the magnitude of the surface stress of the glass pane and $\sigma_{m}$ is the magnitude of the pre-stress in the mid-plane. For more detailed information on the specimen, its production and the stochastic fracture pattern analysis the reader is referred to Pour-Moghaddam (2019) and Kraus (2019). In Fig. 5 the evaluation area is marked by a dashed bounding box, where the left part in clockwise direction of the line is excluded from the evaluation. These areas are not considered for further analysis as due to the geometry of the specimen reflections of the punch-induced Rayleigh wave occur. These reflected Rayleigh waves then interfere with the crack fronts, which propagate at slower velocity as the Rayleigh waves. EN 12150-1 (2015) is followed for deriving the size of the excluded areas (dashed lines).

In Sect. 4.3.1 a thorough discussion of the correlation of the results of this study and the mentioned prior studies Kraus (2019) and Pour-Moghaddam (2019) is given as the very same fragments were used. Quantities of interest here are the cumulative distribution functions of size and shape of the glass fragments obtained by computer vision methods (Kraus 2019) and sieving curves (next section), and the influence of the thickness and pre-stress level versus the strain energy density on the resulting parameters of the Mohr-Coulomb models. 
Table 1 Summary of test specimen properties: thickness $t$, residual surface stress $\sigma_{s}$ and residual midplane stress $\sigma_{m}$, after Pour-Moghaddam (2019)

\begin{tabular}{lllrl}
\hline Specimen & $t[\mathrm{~mm}]$ & $\sigma_{s}[\mathrm{MPa}]$ & $\sigma_{m}[\mathrm{MPa}]$ & $U_{D}\left[\frac{\mathrm{kJ}}{\mathrm{m}^{3}}\right]$ \\
\hline PK1 & 7.7 & -72.9 & 36.3 & 11.60 \\
stdev. & & 1.2 & 0.6 & \\
PK2 & 7.9 & -106.3 & 53.7 & 25.38 \\
stdev. & & 1.3 & 0.9 & \\
PK3 & 12 & -77.7 & 38.4 & 12.98 \\
stdev. & & 2.4 & 1.2 & \\
PK4 & 12 & -110.9 & 55.7 & 27.30 \\
stdev. & & 2.0 & 1.1 & \\
\hline
\end{tabular}

stdev. $=$ standard deviation

\subsection{Geomechanical characterization: test setup and testing parameters}

ISO 17892-10 (2019) basically defines two test schemes to characterize the effective shear strength of a soil. The first experimental setup is called "frame shear test" and the second one is known as "circular ring shear test". Both tests can be used to characterize the maximum as well as the critical shear strength of a geomaterial. Due to the limited number of test specimens available to this work only "framed shear tests" are carried out. Figure 6 shows an exemplary test setup with respect to forcing and measuring devices, cf. Kolymbas (1998), whereas Fig. 7 captures impressions from the actual conduction of the experiments.

The size of the shear frame sample is $100 \mathrm{~mm} \times$ $100 \mathrm{~mm} \times 48 \mathrm{~mm}$, cf. Fig. 7b and the test is carried out displacement controlled with a respective velocity
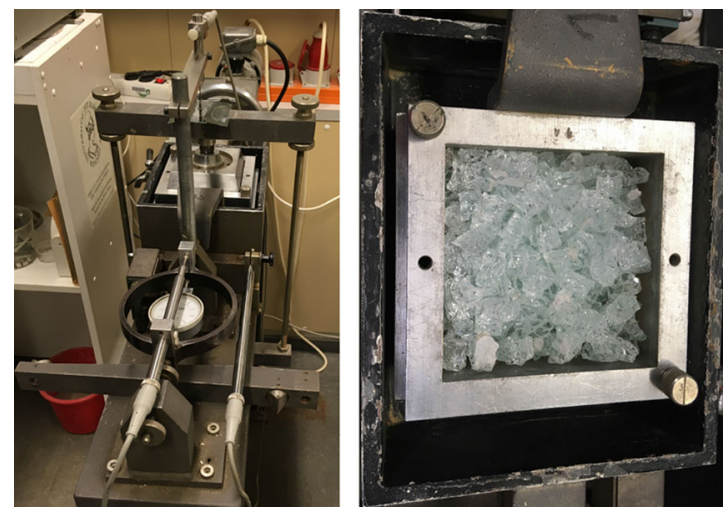

Fig. 7 Impressions from conducting the experiments with the shear frame setup

of $0.1 \frac{\mathrm{mm}}{\mathrm{min}}$. During the test the horizontal displacement (cf. Fig. 6/7), the horizontal force (cf. Fig. 6/9) and the height (Fig. 6/10) of the specimen is measured. The normal force (Fig. 6/1) for each test is kept constant at its respective level. Each specimen was consolidated with the respective normal stress, induced by a constant normal force perpendicular to the shearing plane, for one hour before the test was carried out. However angularity and the porosity of the grains was not measured.

From the basic cross-section area of the shearing plane $(100 \mathrm{~mm} \times 100 \mathrm{~mm})$, the horizontal displacement $u$ and the measured horizontal force $T_{z x}$ are used to compute the respective Cauchy shear stress $\tau_{z x}$ :

$$
\tau_{z x}=\frac{T_{z x}}{b \times(b-u)}
$$

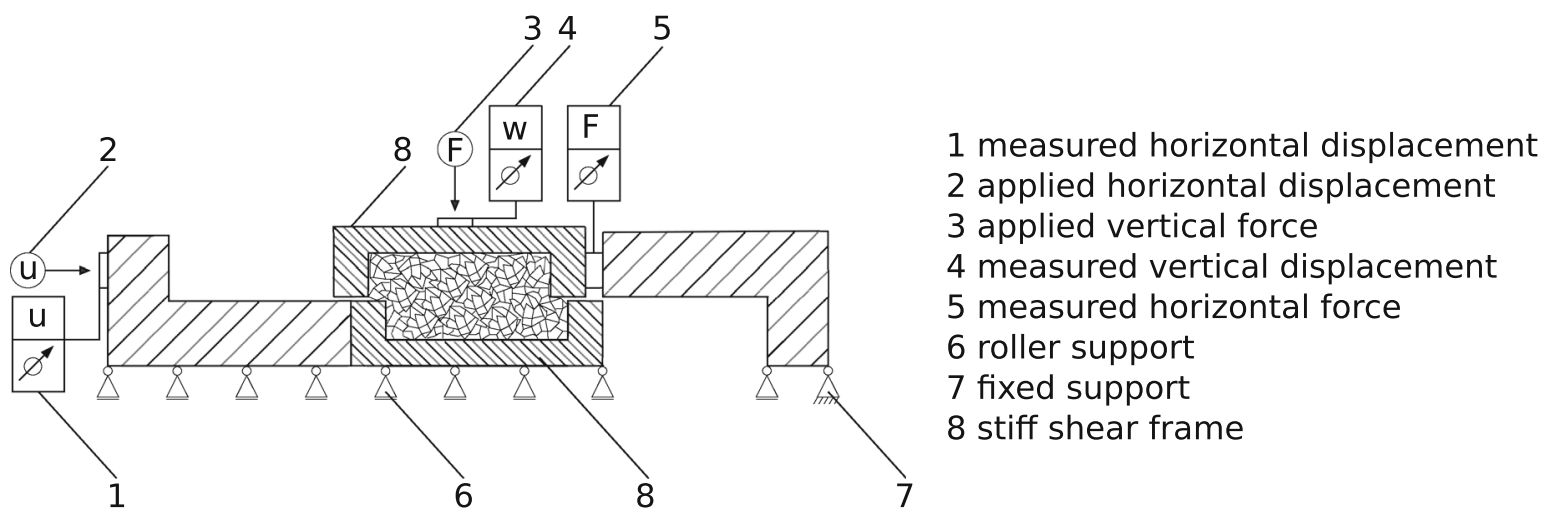

Fig. 6 Test setup of the "frame shear test", ISO 17892-10 (2019) 
Note, that the shear stress given by Eq. (18) is a Cauchy stress, whereas the standard (ISO 17892-10 2019) does not definitely declare whether to use the true or engineering stress measure.

For each specimen three test repetitions are carried out, which differ in the magnitude of applied normal stress in the set $\{100 ; 200 ; 300\} \frac{\mathrm{kN}}{\mathrm{m}^{2}}$. The testing velocity is kept identical for each test repetition. Given the computed shear stresses together with the applied normal stresses it is possible to construct respective shear straights, characterized by a cohesion value and a friction angle (cf. Figs. 11 and 12). The concrete evaluation is explained in more detail in Sect. 4.3.2.

\subsection{Test results}

As mentioned before, two different types of tests are carried out on the fractured glass material. On the one hand side it is the framed shear tests and the other hand side it is the determination of respective sieving curves. The results of both tests are described in more detail in the following subsections.

\subsubsection{Determination of the sieving curve}

According to ISO 17892-10 (2019) the size of the biggest grain should not be larger than $1 / 6$ th of the specimens height, which in the cases under consideration establishes $8 \mathrm{~mm}$. To check if that condition is fulfilled, the glass fragments of each specimen were sifted according to ISO 17892-4 (2015) and respective sieving curves, shown in Fig. 8, were obtained. The sieves used are classified according to ISO 3310-2 (2015).

In Table 2 the amount of particles, that are crushed during the frame shear test, is presented with respect to the specific consolidation load.

The idea is to draw conclusions from the particle size distribution given by the sieving curves in comparison to the cumulative distribution functions of the glass fragment diameters obtained through computer vision in Kraus (2019). As depicted in Fig. 8, the condition according to ISO 17892-10 (2019) is fulfilled and therefore the testing apparatus is appropriate in size to allow the deduction of the sieving lines. According to ISO 14688-1 (2018) the sieving curves of the glass fragments, shown in Fig. 8, lead to the assumption, that the glass fragments can be classified equivalently to fine respectively medium gravel with a regular shape (size

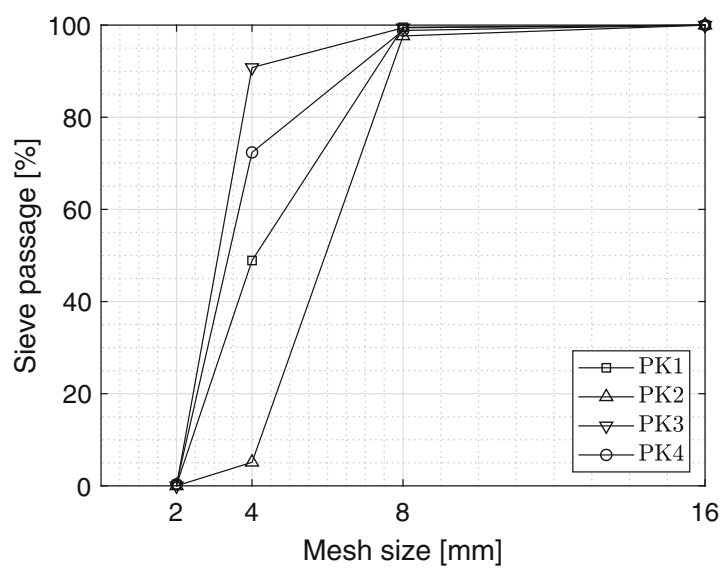

Fig. 8 Sieving curves of the four test specimen

of the fragments between 2 and $20 \mathrm{~mm}$ ). Furthermore the fragments show a regular shape (Degree of nonuniformity $C_{u}=\frac{d_{60}}{d_{10}}=2<6$, DIN 181962011 ; ISO 14688-2 2017). Therefore, the glass fragments show a small specific surface area and few points of contact. This is interesting, as in a mechanical model only at these points of contact a shear strength is associated if normal forces act, such that loads can be carried due to friction (Lang et al. 2010).

Comparing the sieving curves to the properties of the specimens (cf. Table 1), at a first glance it is not possible to obtain clear correlations w.r.t. the respective parameters for geometry and strain energy or stress. Prior to the sieving experiment it was reasoned, that the four sieving curves might show a pairing in two characteristic and distinct pattern lines, as from the stochastic geometry considerations given in Kraus (2019) and Pour-Moghaddam (2019) the fracture particle geometry is mainly driven by the strain energy density $U_{D}$ and not the specimen thickness. As two levels of strain energy density $U_{D}$ (cf. Table 1) are used for this study, the two pattern sieving curve would be plausible, on the other hand side, in contrast to the computer vision investigation on the frontal view of the whole fractured glass pane, the sieving is invariant to the length scales of the glass grain as this always passes with its shortest extension parallel to the sieve.

\subsubsection{Friction angle $\varphi$ and cohesion $c$ for maximum and critical shear stress}

An estimation of the storage density $D$, which is equal to the weight of the glass particles divided by the vol- 
Table 2 Amount of crushed particles for test specimens PK1PK4 with respect to the different levels of consolidation

\begin{tabular}{llll}
\hline [\%] & $100 \frac{\mathrm{kN}}{\mathrm{m}^{2}}$ & $200 \frac{\mathrm{kN}}{\mathrm{m}^{2}}$ & $300 \frac{\mathrm{kN}}{\mathrm{m}^{2}}$ \\
\hline PK1 & 0.27 & 0.47 & 0.85 \\
PK2 & 0.41 & 1.07 & 1.48 \\
PK3 & 0.41 & 0.81 & 1.03 \\
PK4 & 0.63 & 1.30 & 2.19 \\
\hline
\end{tabular}

ume of the test chamber

$$
D=\frac{631.66 \mathrm{~g}}{10 \mathrm{~cm} \times 10 \mathrm{~cm} \times 4.8 \mathrm{~cm}}=1.32 \geq 0.65 \frac{\mathrm{g}}{\mathrm{cm}^{3}}
$$

leads to the assumption of a dense storage (Zou and Boley 2012). The weight of the particles is hereby the mean value of all tests.

Figure 9 shows the measured Cauchy shear stress $\tau_{z x}$ computed according to Eq. 18 with respect to the horizontal displacement $u$ of the frame. Due to the spread in the data, an ensemble of a sliding-average function together with the upper and lower prediction bounds for a 95\% confidence level are depicted in Fig. 9.

Inspection of Fig. 9 is interesting given the typical behaviour of dense and loose sands acc. to Möller (2013) and Lang et al. (2010). Looking at the measured shear-stress-displacement curves for the tested specimen at three distinct levels of normal force, just some can statistically sound be labelled as "dense (supercritical dense) sand" with a characteristic peak in the shearstress-displacement curve. Statistically sound here is interpreted when considering the upper and lower prediction bounds of the test results and comparing maximum and critical shear stress (marked with a red/blue circle) given these confidence bounds it exists a statistically significant difference in these characteristic shear stress values. Within this paper a numerical computation of the test for difference in means for the two shear stresses for all test specimen and normal loadings is omitted given the graphical presentation. Hence the glass fragments mostly show mechanical material behaviour of "loose (subcritical dense) sand" (Möller 2013; Lang et al. 2010), which is in contradiction to the assumption considering the storage density. At this point it is repeated, that the conduction of experiments with glass fracture particles from panes with specifi- cially different levels of pre-stress in such a setting for a greater amount of repetitions was economically prohibitive for this study. In consequence of the limited amount of test specimen available, no statistical evaluation of an ensemble of test repetitions for the investigated specimen and loading conditions could be evaluated to finally proof this observation, whether the specimens can be allocated to loose or dense sand. The amount of available experimental specimens is highly unique and the kind and number of tests were selected carefully to gain as much insight as possible. Nevertheless, in the following the maximum and critical values of the fitted function are evaluated and shown in the respective tables. Based on the outlines in Sect. 3 for post-failure softening relations of the material, the presentation of the results are given in two distinct sets of tables. One contains the results of the maximum shear-stress (Table 3) and one contains the results of the critical shear-stress (Table 4). For the assumption of subcritical dense sand the maximum and critical shear stress coincide and therefore result in the critical shear-stress, hence only Table 4 is necessary. For the assumption of supercritical dense sand the values of the maximum as well as of the critical shear-stress are required (Tables 3 and 4). Figure 10 shows a schematic of the expected trajectories for the results of framed shear and triaxial tests are shown for dense (supercritical dense) and loose (subcritical dense) sand in order to provide a classification of the results of the fractured glass particles.

In the following all graphs of Fig. 9 are evaluated with respect to the maximum and critical shear-stress. Therefore, in each figure, the maximum value of the shear stress (marked with a red circle) corresponds to the maximum shear strength and the value of the shear stress with respect to the largest horizontal displacement (marked with a blue circle) corresponds to the critical shear strength. The largest displacement is defined as $15 \%$ of the inner length of the shear frame.

For each specimen the maximum (cf. Fig. 11) as well as the critical (cf. Fig. 12) shear stresses are plotted against the respective normal stresses. The three resulting pairs of values are then approximated by a straight line defined by a respective inclination, which corresponds to the inner friction angle $\varphi$, and an intersect of the vertical axis, which corresponds to the value of cohesion $c$. Furthermore for each pair of values a Mohr's stress circle, presenting the principal stresses 


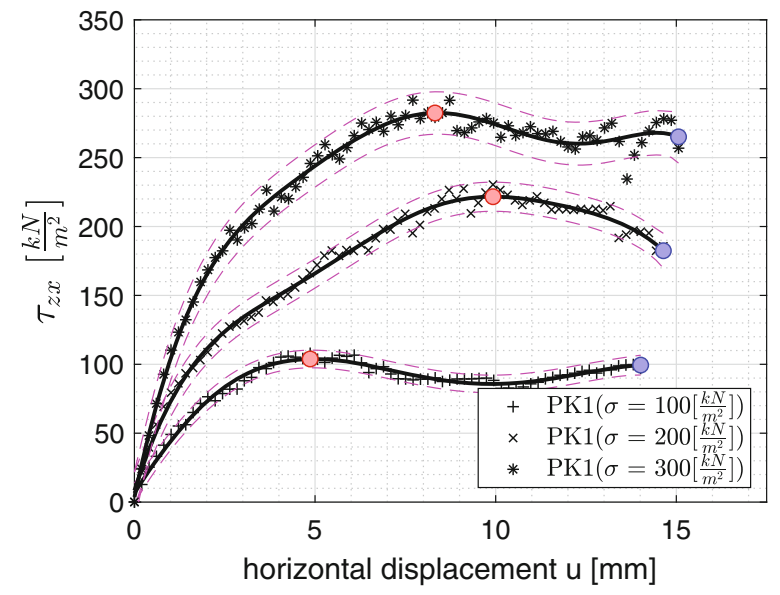

(a)

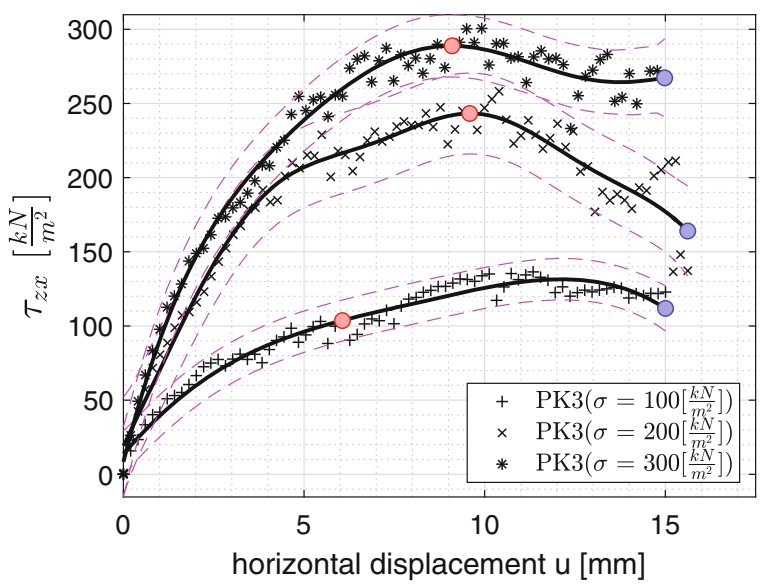

(c)

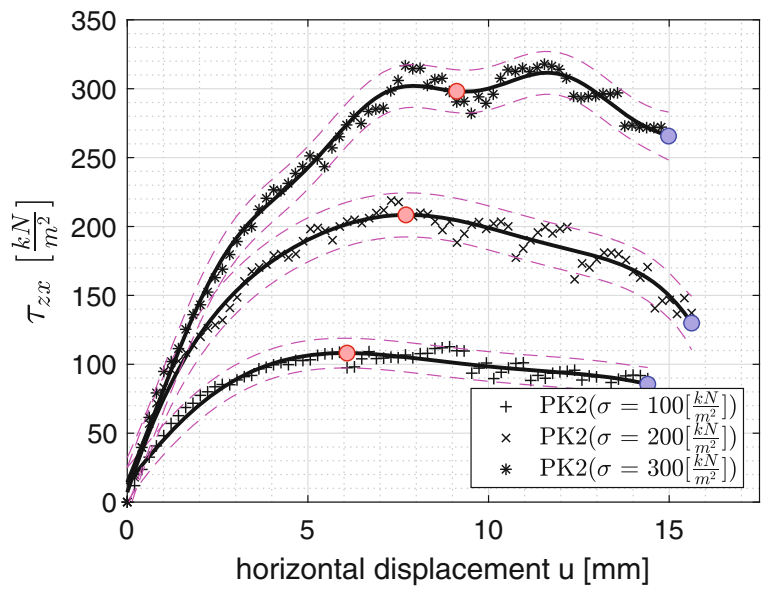

(b)

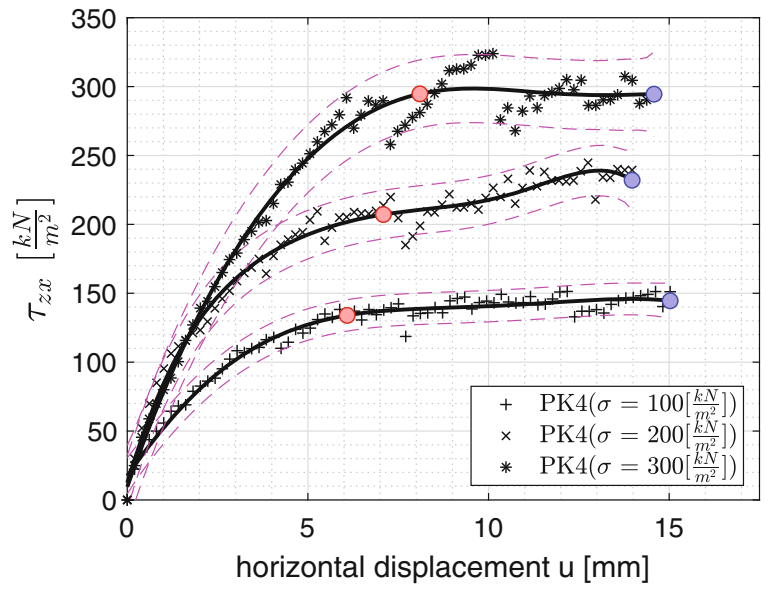

(d)

Fig. 9 Shear stress with respect to displacement for each specimen and load level (red marker: maximum shear stress, blue marker: critical shear stress); results for: a specimen PK1, b specimen PK2, c specimen PK3, d specimen PK4

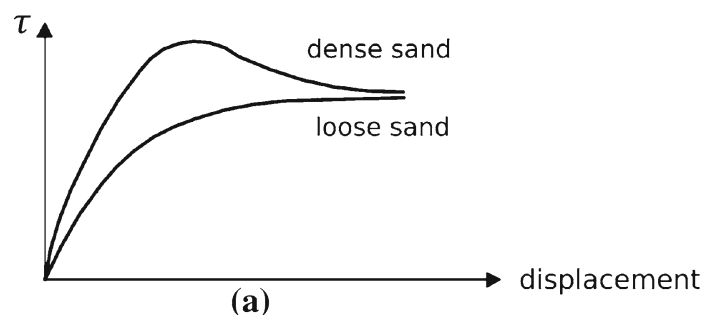

(a)

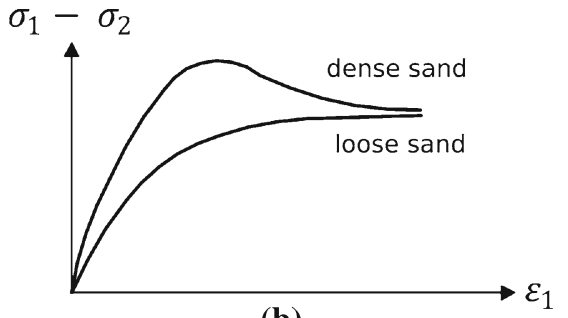

(b)

Fig. 10 Behavior of dense and loose sand for: a framed shear test; $\mathbf{b}$ triaxial test; according to Kolymbas (1998)

at the state of failure, is constructed as follows:

$$
\begin{aligned}
& M=\sigma+\tan (\varphi) \tau \\
& R=\sqrt{\tau^{2}+(\tan (\varphi) \tau)^{2}}
\end{aligned}
$$

For each pair of values an error bar is depicted, which is calculated as follows:

$$
\operatorname{err}=1,96 \frac{\operatorname{stdev} \cdot[X]}{\sqrt{n}}
$$




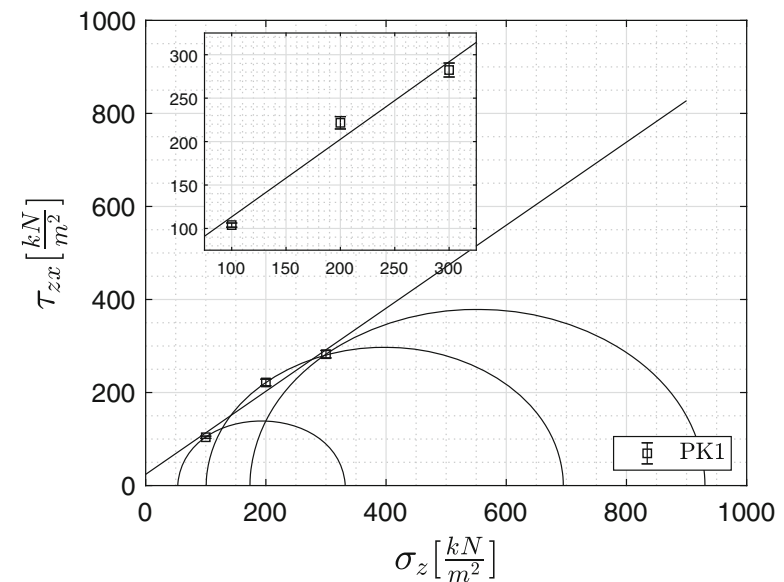

(a)

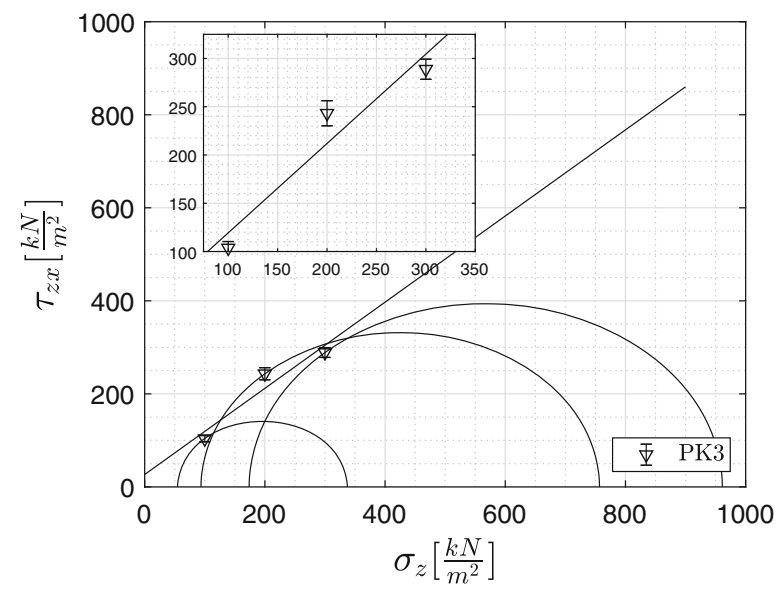

(c)

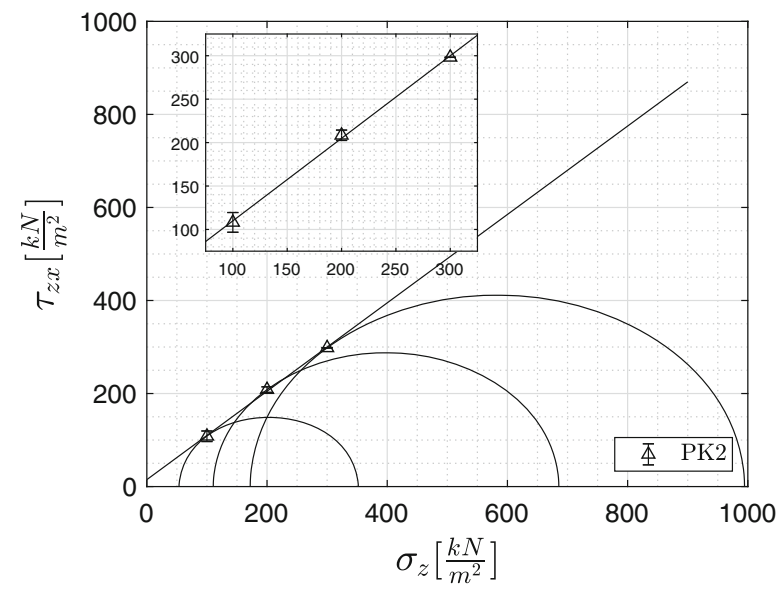

(b)

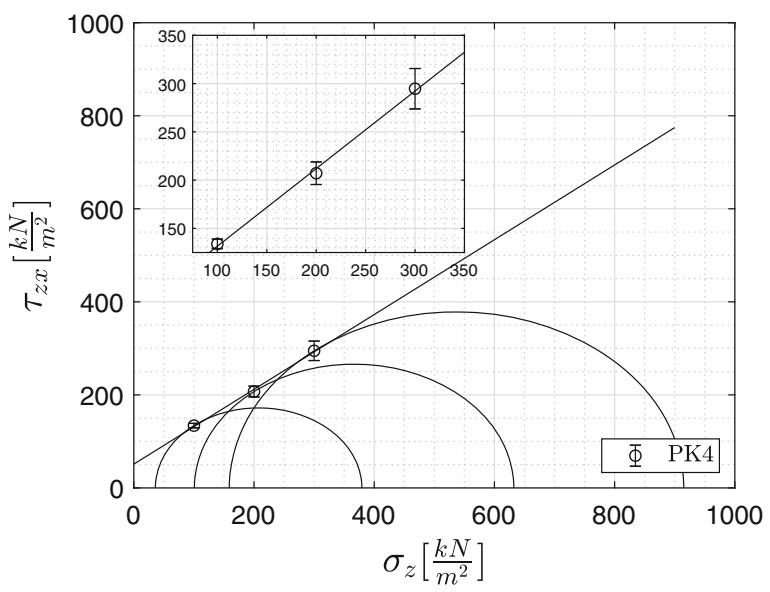

(d)

Fig. 11 Shearlines and respective Mohr's circles, representing the specific maximum shear stress states; results for: a specimen PK1, b specimen PK2, c specimen PK3, d specimen PK4

where stdev. $[X]$ is equal to the standard deviation. The standard deviation of each of the three stress values as presented in each subfigure of Figs. 10 and 11 are computed by considering 5 measured shear stresses before and after the maximum respective critical shear stress and the measured maximum respective critical shear stress itself, $n$ represents the number of random samples and therefore results in 11. The factor 1,96 is used to calculate the $95 \%$ quantile under assumption of zero-mean Gaussian measurement errors. The evaluated angles of inner friction $\varphi$ and values of cohesion $c$ are summarized in Tables 3 and 4 together with the respective strength in tension $f_{t}$ and compression $f_{c}$, evaluated according to Eqs. (13) and (14).
Table 3 Values of cohesion $c$ and friction angle $\varphi$ for the test specimens with respect to the maximum shear stress, together with tensile $f_{t}$ and compression $f_{c}$ yield stresses

\begin{tabular}{lllll}
\hline Specimen & $c\left[\frac{k N}{m^{2}}\right]$ & $\varphi\left[^{\circ}\right]$ & $f_{t}[\mathrm{MPa}]$ & $f_{c}[\mathrm{MPa}]$ \\
\hline PK1 & 24.11 & 41.75 & 0.02 & 0.11 \\
PK2 & 14.89 & 43.53 & 0.01 & 0.07 \\
PK3 & 26.70 & 42.80 & 0.02 & 0.12 \\
PK4 & 51.16 & 38.80 & 0.05 & 0.21 \\
\hline
\end{tabular}

Tables 3 and 4 show the inner friction angle and value of cohesion, evaluated for the maximum as well as the critical shear-stress for each of the specimens. 


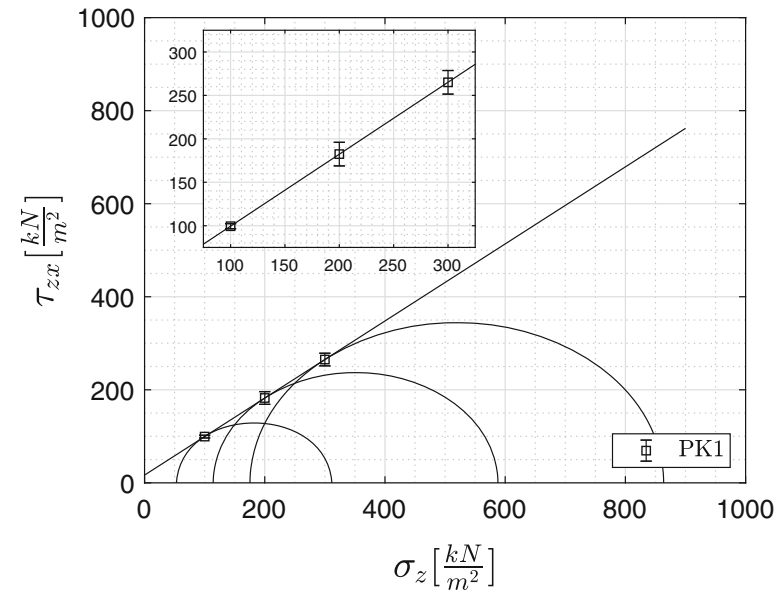

(a)

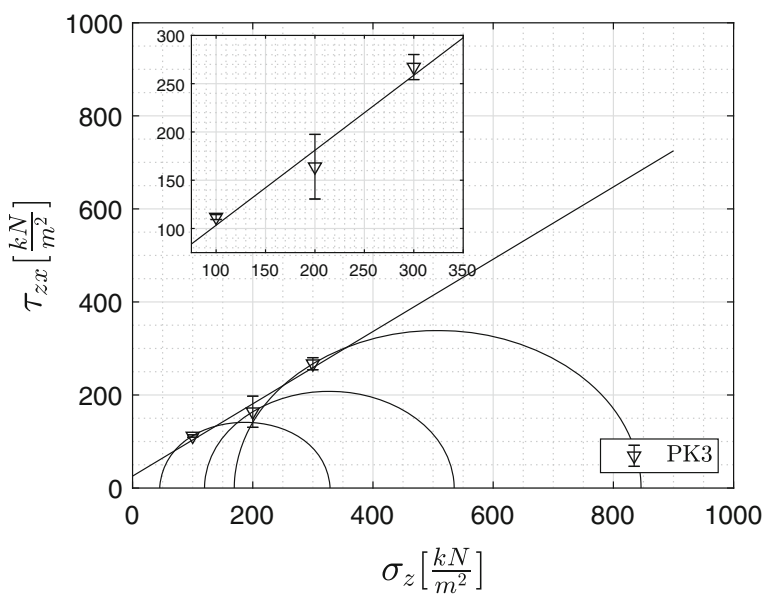

(c)

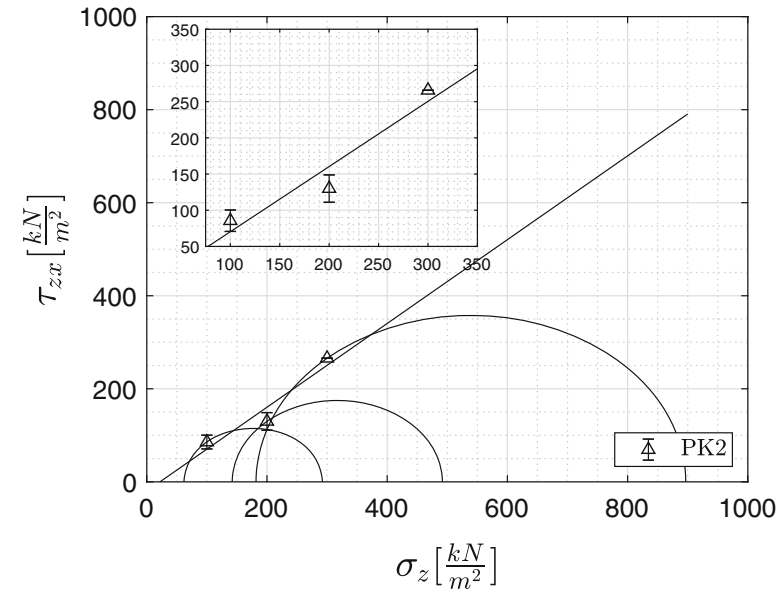

(b)

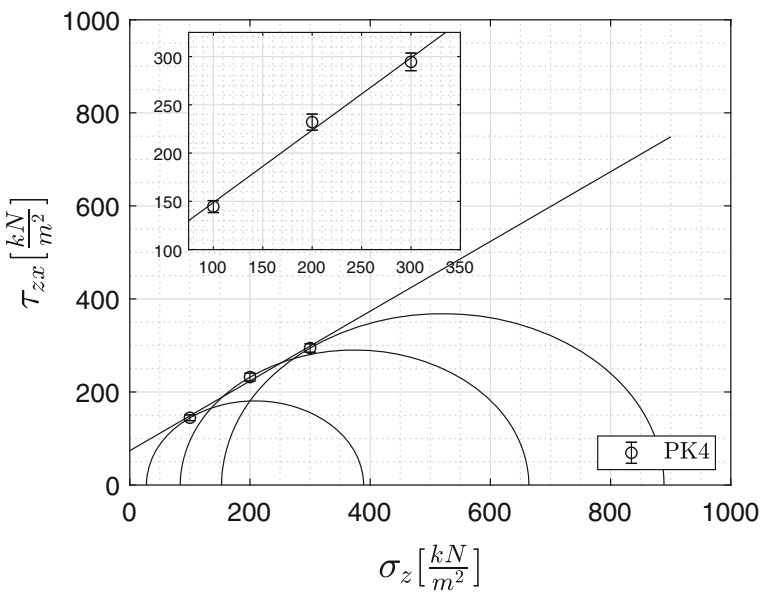

(d)

Fig. 12 Shearlines and respective Mohr's circles, representing the specific critical shear stress states; results for: a specimen PK1, b specimen PK2, c specimen PK3, d specimen PK4

Table 4 Values of cohesion $c_{c}$ and friction angle $\varphi_{c}$ for the test specimens with respect to the critical shear stress, together with tensile $f_{t}$ and compression $f_{c}$ yield stresses

\begin{tabular}{lccll}
\hline Specimen & $c_{c}\left[\frac{\mathrm{kN}}{\mathrm{m}^{2}}\right]$ & $\varphi_{c}\left[^{\circ}\right]$ & $f_{t}[\mathrm{MPa}]$ & $f_{c}[\mathrm{MPa}]$ \\
\hline PK1 & 16.67 & 39.63 & 0.02 & 0.07 \\
PK2 & 0.00 & 42.00 & 0.00 & 0.00 \\
PK3 & 25.64 & 37.84 & 0.03 & 0.10 \\
PK4 & 73.76 & 36.86 & 0.07 & 0.29 \\
\hline
\end{tabular}

Comparing the computed numbers for inner friction angle and value of cohesion, a grouping into two classes w.r.t. either the thickness (PK1, PK2 versus PK3, PK4) or the level of thermal pre-stress (PK1,PK3 versus PK2,PK4) cannot be established. Interestingly it is noted, that the grouping of PK1, PK3 (with same level of pre-stress, cf. Table 1) shows similar values for $\varphi, c$ (cf. Tables 3 and 4) and hence it can be concluded, that despite their different thicknesses, the glass fracture particles behave similarly in mechanical terms, whereas PK2 and PK4 show distinct mechanical behavior. That furthermore leads to the conclusion, that neither the $2 \mathrm{~d}$ computer vision evaluation of the fracture pattern, nor the sieving curve is a reliable estimator for Mohr-Coulomb parameters and establishing a correlation is not possible. 
Table 5 Values of friction angle for the test specimens with respect to the maximum and critical shear stress, considering zero cohesion

\begin{tabular}{lll}
\hline Specimen & $\varphi\left[{ }^{\circ}\right]$ & $\varphi_{c}\left[^{\circ}\right]$ \\
\hline PK1 & 43.98 & 41.29 \\
PK2 & 44.85 & 40.07 \\
PK3 & 45.18 & 40.49 \\
PK4 & 43.75 & 44.16
\end{tabular}

Moreover it is rather untypical, that gravel shows cohesion at all, Zou and Boley (2012). An explanation could be, that the measured cohesion is apparent cohesion. As the crushing is higher at higher stress levels cf. Table 2, the friction angle is less at higher stress levels. In that case, fitting a straight line through the test results does not result in the line going through the origin. Thus, it just seems as if there is cohesion although there is not. However, within that work the cohesion, resulting from the evaluation according to ISO 1789210 (2019), is assumed and the further calculations are based on that. Nevertheless, to provide a complete data set, the respective shear angles for the assumption of no cohesion are depicted in Table 5.

\subsubsection{Determination of the dilatancy angle}

Basically the dilatancy angle describes the increase in volume of the sheared specimen with respect to the shear displacement (as obtained via the framed shear test) and the stretch in volume with respect to the strain in the longitudinal direction (as obtained via a triaxial test), cf. Fig. 13. Usually the triaxial test is preferred for evaluating the dilatancy angle. Nevertheless, due to the limited number of available test specimen for this investigation, the shear frame test is used. The compu- tations for the dilatancy angle $\delta$ are:

$\delta=\arctan \left(\frac{\frac{\Delta V}{V_{0}}}{\frac{\Delta b}{b_{0}}}\right) \frac{180}{\pi}=\arctan \left(\frac{\Delta V b_{0}}{V_{0} \Delta b}\right) \frac{180}{\pi}$

considering $\Delta V=l b(h+s)-l b h, V_{0}=l b h, \Delta b=$ $(b+u)-b, b_{0}=b$ Eq. (23) results in

$$
\begin{aligned}
\delta & =\arctan \left(\frac{[l b(h+s)-l b h] b}{l b h[(b+u)-b]}\right) \frac{180}{\pi} \\
& =\arctan \left(\frac{s b}{h u}\right) \frac{180}{\pi}
\end{aligned}
$$

where $s$ equals the change in height, $u$ equals the displacement in direction of the applied shear force and $l, b, h$ equal the length, width and height of the shear frame. As shown in Fig. 13 the dilatancy is computed with respect to relative values, as it is usually done within the evaluation of the triaxial test. This is due to the fact, that this test is commonly used to determine the dilantancy of soils and furthermore a higher accuracy is expected by such an evaluation. As the dimensions of the specimen are considered.

The blue circles align with those shown in Fig. 9, which depict the location of the critical shear stress, and the red circles depict the intersection between the respective curve and the abscissa. In addition to that, a least squares fit of a straight, combining the graphs of all load levels for each specimen, is computed, as for standard Mohr-Coulomb implementations in Finite Element software just a single number for the dilatancy angle can be provided. This calibrated function starts in the origin and approximates the total change in volume over change in length of the specimen.

As depicted in Fig. 14 at first there is some contraction. This is because grains fit in a somewhat denser pattern. However, shearing further the grains cannot remain in this pattern but have to shift over each other resulting in an increase of volume, measured by the

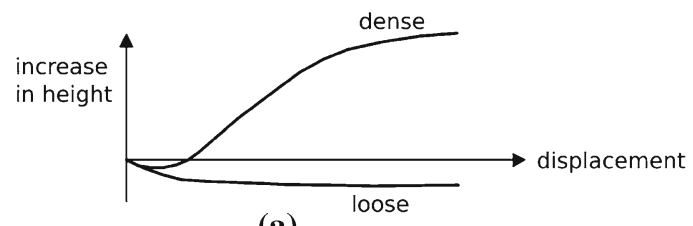

(a)

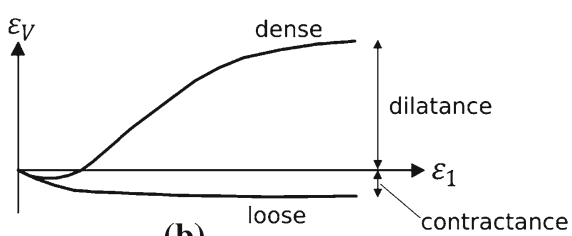

(b)

Fig. 13 Behavior of dense and loose sand for: a framed shear test; $\mathbf{b}$ triaxial test; according to Kolymbas (1998) 


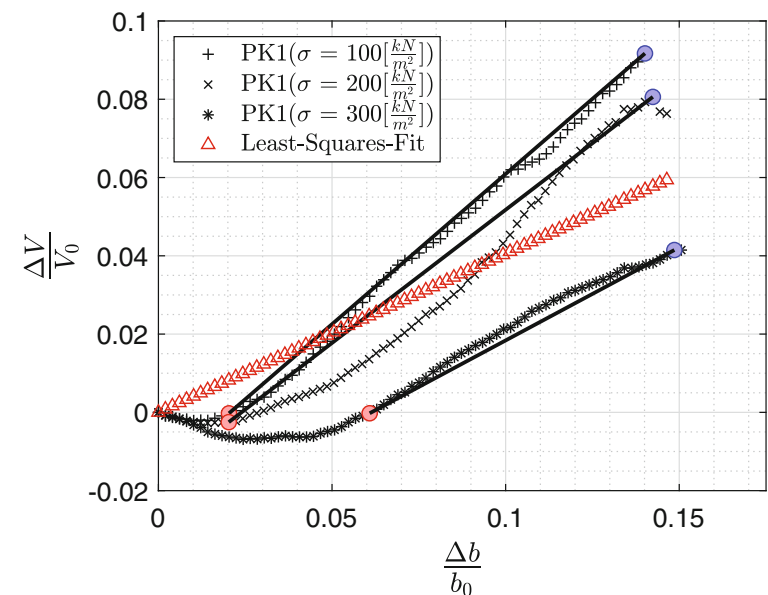

(a)

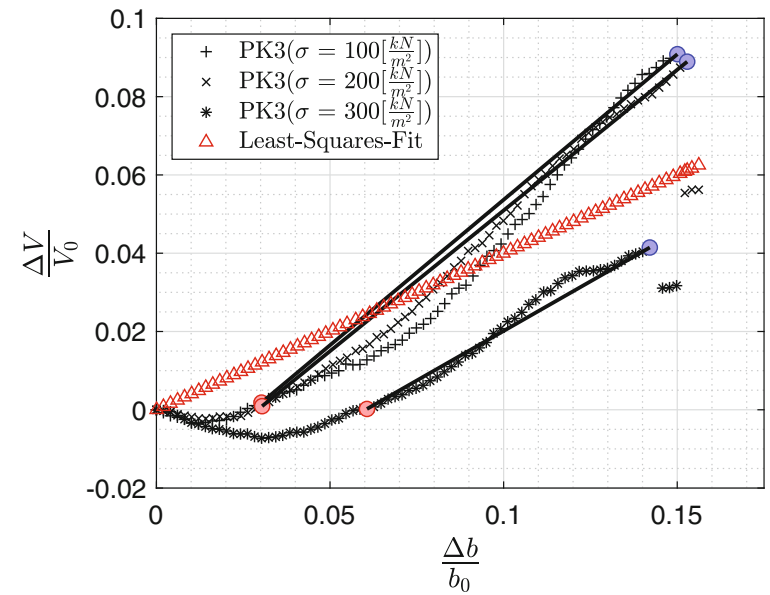

(c)

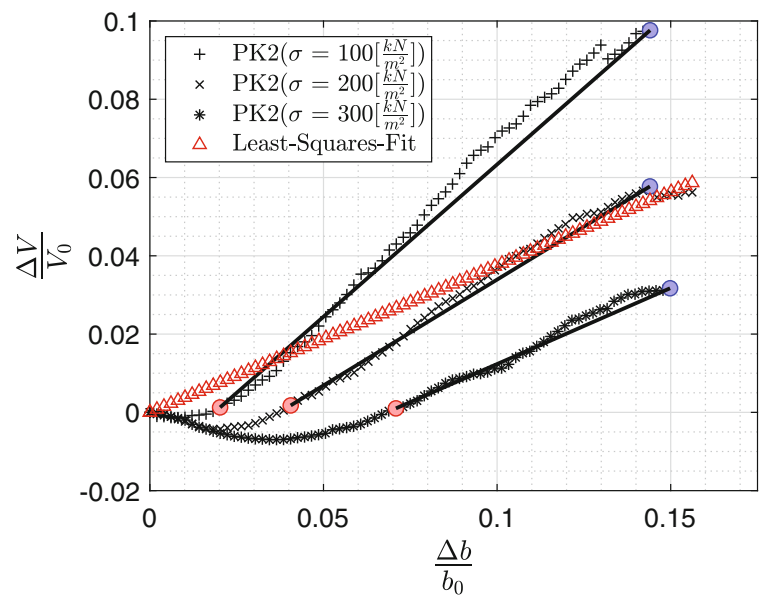

(b)

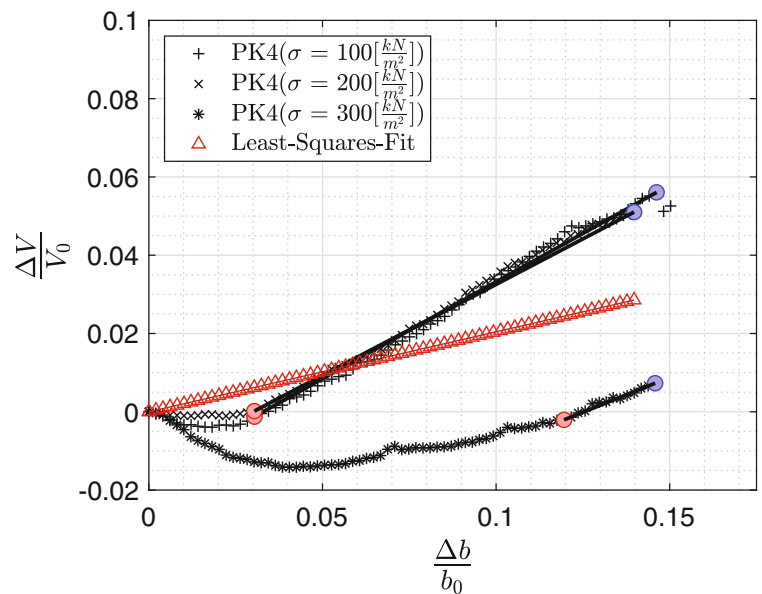

(d)

Fig. 14 Dilatancy angle $\delta$ over normalized displacement for each specimen; a results for: specimen PK1; b specimen PK2, c specimen PK3, d specimen PK4

Table 6 Dilatancy angle $\delta$ for test specimens PK1-PK4 with respect to the consolidation loads and respective mean values

\begin{tabular}{lllll}
\hline$\delta\left[^{\circ}\right]$ & PK1 & PK2 & PK3 & PK4 \\
\hline$\sigma=100\left[\frac{k N}{m^{2}}\right]$ & 37.51 & 37.88 & 36.62 & 26.33 \\
$\sigma=200\left[\frac{k N}{m^{2}}\right]$ & 34.23 & 28.41 & 35.71 & 24.93 \\
$\sigma=300\left[\frac{k N}{m^{2}}\right]$ & 25.42 & 21.24 & 26.86 & 19.62 \\
Mean & 32.39 & 29.18 & 33.06 & 23.63 \\
stdev. & 6.25 & 8.35 & 5.39 & 3.54 \\
Least squares & 22.08 & 20.58 & 21.81 & 11.55
\end{tabular}

angle of dilatancy. This observation together with the comparison between Figs. 13 and 14 would lead to the assumption, that the glass fragments behave similar to dense sand. As that contradicts the observation made from the shearing curves, it is again shown, that a clear statement whether glass fragments can be allocated at dense or loose sand cannot be made. However the decrease in volume, which can be observed for small displacements, coincides with the observations made during the testing of further crushing of the fragments (cf. Fig. 2). 
Table 7 Parameters for Mohr-Coulomb material modelSpecimen PK1

\begin{tabular}{lll}
\hline Friction angle (initial) $\varphi$ & 41.75 & {$\left[{ }^{\circ}\right]$} \\
\hline Cohesion (initial) $c$ & 24.11 & {$\left[\frac{\mathrm{kN}}{\mathrm{m}^{2}}\right]$} \\
Dilatancy angle $\delta$ & 32.39 & {$\left[{ }^{\circ}\right]$} \\
Friction angle (remaining) $\varphi_{c}$ & 39.63 & {$\left[{ }^{\circ}\right]$} \\
Cohesion (remaining) $c_{c}$ & 16.67 & {$\left[\frac{\mathrm{kN}}{\mathrm{m}^{2}}\right]$} \\
\hline
\end{tabular}

Table 8 Parameters for Mohr-Coulomb material modelSpecimen PK2

\begin{tabular}{lll}
\hline Friction angle (initial) $\varphi$ & 43.53 & {$\left[{ }^{\circ}\right]$} \\
\hline Cohesion (initial) $c$ & 14.89 & {$\left[\frac{\mathrm{kN}}{\mathrm{m}^{2}}\right]$} \\
Dilatancy angle $\delta$ & 29.18 & {$\left[^{\circ}\right]$} \\
Friction angle (remaining) $\varphi_{c}$ & 42.00 & {$\left[{ }^{\circ}\right]$} \\
Cohesion (remaining) $c_{c}$ & 0.00 & {$\left[\frac{\mathrm{kN}}{\mathrm{m}^{2}}\right]$}
\end{tabular}

Table 9 Parameters for Mohr-Coulomb material modelSpecimen PK3

\begin{tabular}{lll}
\hline Friction angle (initial) $\varphi$ & 42.80 & {$\left[{ }^{\circ}\right]$} \\
\hline Cohesion (initial) $c$ & 26.70 & {$\left[\frac{\mathrm{kN}}{\mathrm{m}^{2}}\right]$} \\
Dilatancy angle $\delta$ & 33.06 & {$\left[{ }^{\circ}\right]$} \\
Friction angle (remaining) $\varphi_{c}$ & 37.84 & {$\left[{ }^{\circ}\right]$} \\
Cohesion (remaining) $c_{c}$ & 25.64 & {$\left[\frac{\mathrm{kN}}{\mathrm{m}^{2}}\right]$}
\end{tabular}

\subsubsection{Calibrated Mohr-Coulomb material parameters for each specimen}

In this subsection, the obtained parameters for the respective Mohr-Coulomb material models are summarized in tabular form. For the dilatancy angle, the mean values of Table 6 are chosen.

Given these data it is possible to simulate the respective test specimen and similar glass fracture particles with a non-associated Mohr-Coulomb material model within a Finite Element Analysis context (Tables 7, 8, 9 and 10), which is subject to the next section.
Table 10 Parameters for Mohr-Coulomb material modelSpecimen PK4

\begin{tabular}{lll}
\hline Friction angle (initial) $\varphi$ & 38.80 & {$\left[{ }^{\circ}\right]$} \\
\hline Cohesion (initial) $c$ & 51.16 & {$\left[\frac{\mathrm{kN}}{\mathrm{m}^{2}}\right]$} \\
Dilatancy angle $\delta$ & 23.63 & {$\left[{ }^{\circ}\right]$} \\
Friction angle (remaining) $\varphi_{c}$ & 36.86 & {$\left[{ }^{\circ}\right]$} \\
Cohesion (remaining) $c_{c}$ & 73.76 & {$\left[\frac{\mathrm{kN}}{\mathrm{m}^{2}}\right]$} \\
\hline
\end{tabular}

\section{Finite element model validation}

In the previous section, experimental data were used to derive respective parameters of Mohr-Coulomb constitutive models, which in this section serve to calibrate Finite Element models in order to allow further simulation and sensitivity studies. All simulations within this paper are conducted with ANSYS 2020R. In Fig. 15 the geometry (a) boundary conditions (b) and (c) the mesh for the Finite Element system is shown.

As described in Sect. 4, the frame shear experiments consisted of a $48 \mathrm{~mm}$ in-total-height bulk material, which was sheared in the middle plane at $Y=24 \mathrm{~mm}$. In order to avoid modelling the shear frames and complicated contact definitions of the glass particle bulk material and the shear frame box, an effective total height of $24 \mathrm{~mm}$ was assumed for the ANSYS geometry model as an approximation, cf. Fig. 15a. This effective total height is deduced from considering a rectangular normal stress distribution on the faces of the shear frame in contact with the glass bulk material, which possess an inner lever arm of $2 \cdot(48 / 2) / 2 \mathrm{~mm}$ $=24 \mathrm{~mm}$. The material modelling of the fractured glass particles moreover allows several numerical investigations, which are conducted within the scope of this validation and sensitivity analysis:

- Mohr-Coulomb without dilatation

- Mohr-Coulomb with dilatation

- influence of the parameters of linear elasticity $E, v$ of the fractured glass particles prior to yielding.

A consistent calibration of the parameters of linear elasticity $E, K, v$ of the fractured glass particles prior to yielding is not possible given the data from the shear frame test, as just information on the isochoric deformation parts and the dilatation (Jacobian $J=\operatorname{det}(\mathbf{F})$ ) are available. The conduction and evaluation of triaxial experiments would provide sufficient information 


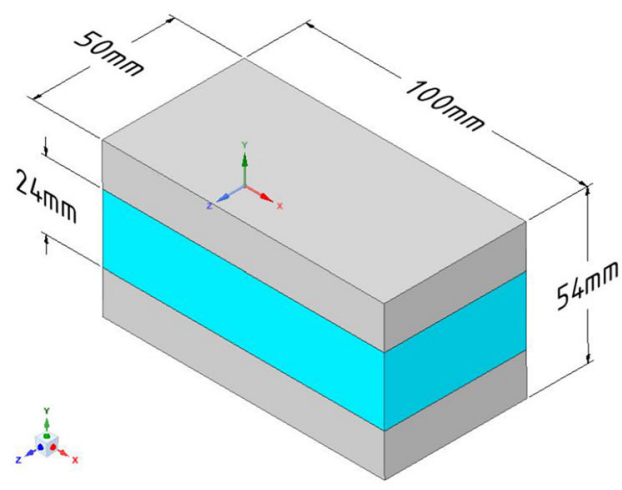

(a)

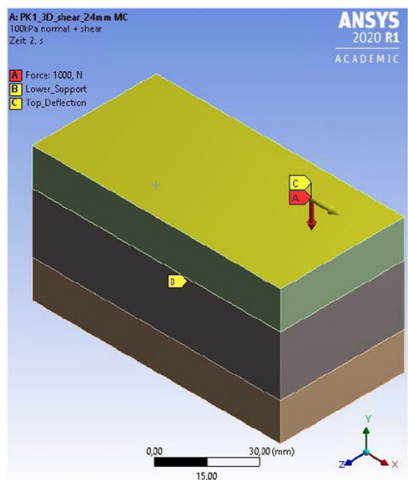

(b)

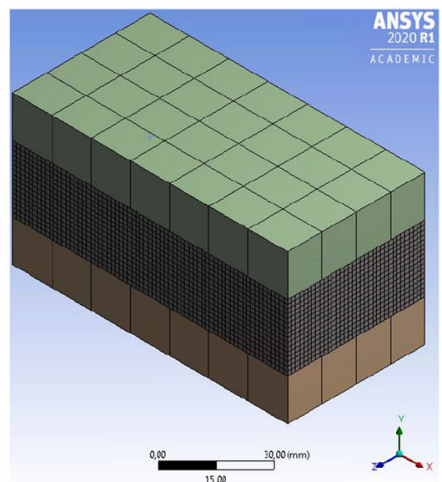

(c)

Fig. 15 Ansys model of the frame shear test: a geometry $\mathbf{b}$ boundary conditions $\mathbf{c}$ mesh

in that respect. This however was prohibited given the available volume amount of glass fragments at a certain pre-stress level for this study, as the production of such specimen is demanding from a monetary and temporal point of view. The deduction of suitable parameters for the pre-yield linear elasticity is based on the shear stress - shear angle graph of the test specimen for two chosen Poisson's ratios within this investigation. Based on Fig. 14, the material parameter for the pre-yield are chosen to be $(\nu ; E)=\{(0.23 ; 7.4) ;(0.48 ; 9.0)\}[-; \mathrm{MPa}]$. Interestingly these values are in line with the magnitude range of Poisson's ratios and Young's moduli for sand.In Table 11 the respective material parameters for the FE analysis are depicted. The sand-like mechanical behavior of fractured pre-stressed glass was already recognized in Sects. 4.3.1 and 4.3.2. Given the main scope and brevity of this paper, just results of the Finite Element model validation and sensitivity analysis for test specimen PK1 are shown, cf. Fig. 16. Further results of and details on the numerical investigations and modelling strategies such as using Drucker-Prager plasticity etc. will be presented in a future paper by the authors in more detail.

Inspection of Fig. 16 allows for several conclusions. The models with nearly incompressible material behavior (yellow and blue lines) show a too stiff initial material behavior, where the model without dilatancy overestimates the measured force reaction by a factor of up to 1.5. The initial nearly incompressible material behavior could be concluded from the dilatancy graphs, however the curves with the Poisson's ratio of $v=0.23$ (green and orange lines), which is also the Poisson's ratio of intact glass and sandy geoma- terials, fits the experimental observations better. Interestingly the compressible Mohr-Coulomb model with dilatancy (green line) can capture the softening after maximum shear force. As already stated, the main focus of this paper is to present the experimental investigations and the elaboration of a general validation of a Finite Element Model for fracture particles from prestressed glass by means of a Mohr-Coulomb plasticity model, further analysis of the numerical investigations will be presented in a future paper. At this stage however, the general validity and plausibility of the parameters deduced from the presented experiments within a Finite Element Modelling framework can be proved.

\section{Summary, conclusions and outlook}

This paper is concerned with the conduction and evaluation of geomechanical experiments on glass fracture particles obtained from fracturing thermally prestressed glass specimen with different levels of prestress and thicknesses. Further analysis of the experimental data allowed the deduction of the parameters for models of the Mohr-Coulomb plasticity type in order to enable numerical analysis within the Finite Element Method of the glass fracture particles and fractured glass laminates made from tempered glasses. This investigation is inspired form the constitutive modelling approaches of geotechnical materials and the respective experimental characterization methods for deriving material parameters.

Within this paper, the general setting for using plasticity models within a Finite Element context in order to 
Fig. 16 Results of the finite element investigations with different Mohr-Coulomb material modelling choices (compare Table 11) for specimen PK1

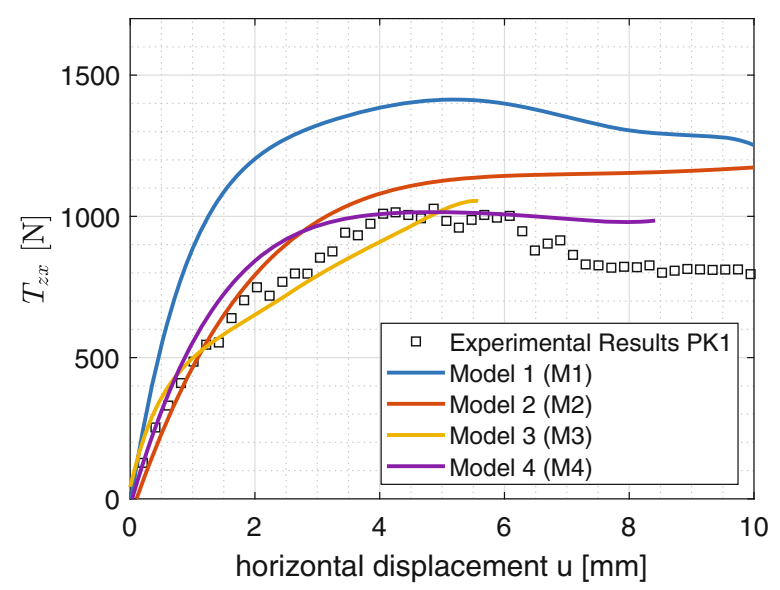

Table 11 Parameters for the FE analysis

\begin{tabular}{|c|c|c|c|c|c|}
\hline Model & M1 & M2 & M3 & M4 & \\
\hline Young's modulus & 9 & 7.4 & 9 & 7.4 & {$[\mathrm{MPa}]$} \\
\hline Poisson's ratio & 0.48 & 0.23 & 0.48 & 0.23 & {$[-]$} \\
\hline Friction angle (initial) $\varphi$ & 41.75 & 41.75 & 41.75 & 41.75 & {$\left[{ }^{\circ}\right]$} \\
\hline Cohesion (initial) $c$ & 0.024 & 0.024 & 0.024 & 0.024 & [MPa] \\
\hline Dilatancy angle $\delta$ & 41.75 & 41.75 & 32.39 & 32.39 & {$\left[{ }^{\circ}\right]$} \\
\hline Friction angle (remaining) $\varphi_{c}$ & 41.75 & 41.75 & 39.63 & 39.63 & {$\left[{ }^{\circ}\right]$} \\
\hline Cohesion (remaining) $c_{c}$ & 0.024 & 0.024 & 0.017 & 0.017 & [MPa] \\
\hline
\end{tabular}

numerically model fractured glass particles and fractured glass laminates was elaborated and described. For reasons of brevity of this article, the discussion on models of plasticity for describing the glass particles is restricted to the material model and failure criterion of the Mohr-Coulomb type, where the associated interpretation is discussed in detail and set into context with the experimental findings. The correlation of the obtained sieving curves to the diameters of the glass fractures and the statistical distribution (as provided by Kraus 2019) of the diameter as a function of glass thickness and pre-stress level was not possible. The conclusion here is, that the mesh size of the standard sieves for geotechnical investigations is too coarse on the one hand side and on the other hand side, the orientation of the glass fracture particle during passage of the sieve mesh is likely to not be maximum diameter and thus censors the obtained diameter distribution by the sieve. It then was shown, that the experimental setup is suited for obtaining relevant results in terms of shear stress displacement and dilatancy - displacement, which subsequently can be processed to obtain the parameters initial cohesion $c$, initial friction angle $\varphi$ and dilatancy angle $v$ as well as the residual cohesion $c_{c}$ and residual friction angle $\varphi_{c}$ for Mohr-Coulomb material models. Given the available amount of glass fracture particles, it was not possible to conduct triaxial experiments to further verify the data from the frame shear test. It was obtained, that classifying the distinct glass fracture particles w.r.t. their respective thicknesses or initial strain energy densities into groups of mechanically similar shearing behavior is not possible in general, however for a level of internal energy of $U_{D} \approx 12 \frac{\mathrm{kJ}}{\mathrm{m}^{3}}$ similar values for cohesion $c$ and friction angle $\varphi$ are obtained. This leads to the conclusion, that simulating glass fracture particles with different thicknesses and/or levels of thermal pre-stress need distinct Mohr-Coulomb plasticity models. Furthermore, the assumption of a constant dilatancy angle within the Mohr-Coulomb models has to be questioned critically. As shown by the test results the dilatancy angle constantly changes with respect to the deformation. If the angle is considered to be a constant value corresponding to the change in volume, the volumetric deformation and stress parts 
are overestimated. However, given the simplicity of the Mohr-Coulomb model this modelling assumption can be viewed as a first approximation step, where the data reported within this paper allow for the calibration of more complicated constitutive models of fractured glass. The validation of the Finite Element model for recapturing the experimental results in a numerical manner was possible. There it was noted, that the solution behavior was cumbersome in terms of convergence, a sensitivity study with reasonable parameters for the fractured glass particles proves, that a Finite Element model could reproduce the obtained experiments.

Future work is concerned with the investigation of alternative models of plasticity such as DruckerPrager, which also can be calibrated given the presented database (Kraus and Pauli, 2021). The focus there will also ly in finding models, which are able to reproduce the non-constant dilatancy. A greater numerical sensitivity analyses by means of several Finite Element investigations will reassess all tests to gain further insight into the computational modelling of fractured glass particles by means of plasticity models.

Acknowledgements We would like to thank Dr.-Ing. Navid Pour-Moghaddam for providing the test specimen to us for further analysis. Furthermore we would like to thank Prof. Dr.-Ing. Boley and his laboratory, especially M.Sc. Michael Herrmann (Bundeswehr University Munich) for the support in conducting the experiments.

Funding Open Access funding enabled and organized by Projekt DEAL.

\section{Compliance with ethical standards}

Conflicts of interest The authors declare that there is no conflict of interests.

Open Access This article is licensed under a Creative Commons Attribution 4.0 International License, which permits use, sharing, adaptation, distribution and reproduction in any medium or format, as long as you give appropriate credit to the original author(s) and the source, provide a link to the Creative Commons licence, and indicate if changes were made. The images or other third party material in this article are included in the article's Creative Commons licence, unless indicated otherwise in a credit line to the material. If material is not included in the article's Creative Commons licence and your intended use is not permitted by statutory regulation or exceeds the permitted use, you will need to obtain permission directly from the copyright holder. To view a copy of this licence, visit http://creativecommons.org/licenses/ by $/ 4.0 /$.

\section{References}

Aenlle, M.L., Pelayo, F., Ismael, G.: An effective thickness to estimate stresses in laminated glass beams under dynamic loadings. Compos. Part B Eng. 82, 1-12 (2015)

Al-Ajmi, A.M., Zimmerman, R.W.: Stability analysis of vertical boreholes using the Mohr-Coulomb failure criterion. Int. J. Rock Mech. Min. Sci. 43(8), 1200-1211 (2006)

Altenbach, H: Materialverhalten und konstitutivgleichungen. In: Kontinuumsmechanik, pp. 211-232. Springer, Berlin (2012)

Anand, L., Gu, C.: Granular materials: constitutive equations and strain localization. J. Mech. Phys. Solids 48(8), 1701-1733 (2000)

Asik, M.Z., Tezcan, S.: A mathematical model for the behavior of laminated glass beams. Comput. Struct. 83(21-22), 17421753 (2005)

Baraldi, D., Cecchi, A., Foraboschi, P.: Broken tempered laminated glass: non-linear discrete element modeling. Compos. Struct. 140, 278-295 (2016)

Behr, R.A., Minor, J.E., Linden, M.P., Vallabhan, C.V.G.: Laminated glass units under uniform lateral pressure. J. Struct. Eng. 111(5), 1037-1050 (1985)

Behr, R.A., Minor, J.E., Norville, H.S.: Structural behavior of architectural laminated glass. J. Struct. Eng. 119(1), 202222 (1993)

Belis, J., Depauw, J., Callewaert, D., Delincé, D., Van Impe, R.: Failure mechanisms and residual capacity of annealed glass/SGP laminated beams at room temperature. Eng. Fail. Anal. 16(6), 1866-1875 (2009)

Bićanić, N., et al.: On multivector stress returns in MohrCoulomb plasticity. In: Proceedings of the Second International Conference on Computational Plasticity: Models, Software and Applications, pp. 421-436. Pineridge Press, Swansea (1989)

Bigoni, D., Piccolroaz, A.: Yield criteria for quasibrittle and frictional materials. Int. J. Solids Struct. 41(11-12), 2855-2878 (2004)

Biolzi, L., Cattaneo, S., Rosati, G.: Progressive damage and fracture of laminated glass beams. Constr. Build. Mater. 24(4), 577-584 (2010)

Biolzi, L., Orlando, M., Piscitelli, L.R., Spinelli, P.: Static and dynamic response of progressively damaged ionoplast laminated glass beams. Compos. Struct. 157, 337-347 (2016)

Borja, R.I., Sama, K.M., Sanz, P.F.: On the numerical integration of three-invariant elastoplastic constitutive models. Comput. Methods Appl. Mech. Eng. 192(9-10), 1227-1258 (2003)

Botz, M., Kraus, M.A., Siebert, G.: Untersuchungen zur thermomechanischen modellierung der resttragfähigkeit von verbundglas. ce/papers 3(1), 125-136 (2019)

Byerlee, J.: Friction of rocks. In: Rock friction and earthquake prediction, pp. 615-626. Springer, Berlin (1978)

Castori, G., Speranzini, E.: Structural analysis of failure behavior of laminated glass. Compos. Part B Eng. 125, 89-99 (2017)

Chen, S., Zang, M., Wang, D., Yoshimura, S., Yamada, T.: Numerical analysis of impact failure of automotive laminated glass: a review. Compos. Part B Eng. 122, 47-60 (2017) 
D’Ambrosio, G., Galuppi, L., Royer-Carfagni, G.: A simple model for the post-breakage response of laminated glass under in-plane loading. Compos. Struct. 230, 111426 (2019)

Das, B.M., Sivakugan, N.: Fundamentals of Geotechnical Engineering. Cengage Learning (2016)

De Borst, R.: Integration of plasticity equations for singular yield functions. Comput. Struct. 26(5), 823-829 (1987)

DIN 18196. Earthworks and foundations-soil classification for civil engineering purposes (2011)

Dunne, F., Petrinic, N.: Introduction to Computational Plasticity. Oxford University Press on Demand, Oxford (2005)

EN 12150-1. Glass in building - thermally toughened soda lime silicate safety glass - part 1: Definition and description (2015)

Fahlbusch, M.: Zur Ermittlung der Resttragfähigkeit von Verbundsicherheitsglas am Beispiel eines Glasbogens mit Zugstab. PhD thesis, Technische Universität (2008)

Feirabend, S.: Steigerung der resttragfähigkeit von verbundsicherheitsglas mittels bewehrung in der zwischenschicht (2010)

Feirabend, S., Sobek, W.: Bewehrtes verbundsicherheitsglas. Stahlbau 77(S1), 16-22 (2008)

Feldmann, M., Kaspar, R., Abeln, B., Gessler, A., Langosch, K., Beyer, J., Schneider, J., Schula, S., Siebert, G., Haese, A., et al.: Guidance for European Structural Design of Glass Components. Publications Office of the European Union (2014)

Foraboschi, P.: Analytical solution of two-layer beam taking into account nonlinear interlayer slip. J. Eng. Mech. 135(10), 1129-1146 (2009)

Franz, J.: Untersuchungen zur Resttragfähigkeit von gebrochenen Verglasungen: Investigation of the residual loadbearing behaviour of fractured glazing, vol. 45. Springer, Berlin (2015)

Fröling, M., Persson, K.: Computational methods for laminated glass. J. Eng. Mech. 139(7), 780-790 (2013)

Fröling, M., Persson, K., Austrell, P.-E.: A reduced model for the design of glass structures subjected to dynamic impulse load. Eng. Struct. 80, 53-60 (2014)

Fung, Y. C.: A first course in continuum mechanics Englewood Cliffs, N.J., Prentice-Hall, Inc. (1977)

Galuppi, L., Royer-Carfagni, G.F.: Effective thickness of laminated glass beams: new expression via a variational approach. Eng. Struct. 38, 53-67 (2012)

Galuppi, L., Royer-Carfagni, G.: A homogenized model for the post-breakage tensile behavior of laminated glass. Compos. Struct. 154, 600-615 (2016)

Galuppi, L., Royer-Carfagni, G.: A homogenized analysis à la Hashin for cracked laminates under equi-biaxial stress. applications to laminated glass. Compos. Part B Eng. 111, 332-347 (2017)

Galuppi, L., Royer-Carfagni, G.: The post-breakage response of laminated heat-treated glass under in plane and out of plane loading. Compos. Part B Eng. 147, 227-239 (2018)

Gurtin, M.E.: An Introduction to Continuum Mechanics. Academic Press, London (1982)

He, P., Kulatilake, P.H.S.W., Yang, X., Liu, D., He, M.: Detailed comparison of nine intact rock failure criteria using polyaxial intact coal strength data obtained through PFC 3D simulations. Acta Geotech. 13(2), 419-445 (2018)
Holtz, R.D., Kovacs, W.D., Sheahan, T.C.: An Introduction to Geotechnical Engineering, vol. 733. Prentice-Hall, Englewood Cliffs (1981)

Hooper, J.A.: On the bending of architectural laminated glass. Int. J. Mech. Sci. 15(4), 309-323 (1973)

ISO 17892-4. Geotechnical investigation and testinglaboratory testing of soil-part 4: determination of particle size distribution (2015)

ISO 3310-2. Test sieves - technical requirements and testingpart 2: test sieves of perforated metal plate (2015)

ISO 14688-2. Geotechnical investigation and testingidentification and classification of soil-part 2: principles for a classification (2017)

ISO 14688-1. Geotechnical investigation and testing - identification and classification of soil-part 1: identification and description (2018)

ISO 17892-10. Geotechnical investigation and testinglaboratory testing of soil—part 10: direct shear tests (2019)

Ivanov, I.V.: Analysis, modelling, and optimization of laminated glasses as plane beam. Int. J. Solids Struct. 43(22-23), 6887-6907 (2006)

Jaeger, J.C., Cook, N.G.W., Zimmerman, R.: Fundamentals of Rock Mechanics. Wiley, London (2009)

Jaśkowiec, J., Pluciński, P., Stankiewicz, A., Cichoń, C.: Threedimensional modelling of laminated glass bending on twodimensional in-plane mesh. Compos. Part B Eng. 120, 6382 (2017)

Jeltsch-Fricker, R., Meckbach, S.: Parabolische mohrsche bruchbedingung in invariantendarstellung für spröde isotrope werkstoffe. ZAMM-J. Appl. Math. Mech./Zeitschrift für Angewandte Mathematik und Mechanik: Applied Mathematics and Mechanics 79(7), 465-471 (1999)

Johansen, K.W.: Yield-Line Theory. Cement and Concrete Association (1962)

Katzenbach, R.: Anwendung der fem in der geotechnik. Institut und Versuchsanstalt für Geotechnik - TU Darmstad (2013)

Kolymbas, D.: Geotechnik. Springer, Berlin (1998)

Kott, A., Vogel, T.: Safety of laminated glass structures after initial failure. Struct. Eng. Int. 14(2), 134-138 (2004)

Kott, A., Vogel, T.: Versuche zum Trag-und Resttragverhalten von Verbundsicherheitsglas. Number 296. vdf Hochschulverlag AG (2006)

Kraus, M.A.: Machine learning techniques for the material parameter identification of laminated glass in the intact and post-fracture state. Ph.D. thesis, Dissertation, Universität der Bundeswehr München (2019)

Kraus, M.A., Pourmoghaddam, N., Siebert, G., Schneider, J.: Statistische auswertung und vorhersage des bruchbildes von thermisch vorgespanntem glas. Ce/papers 3(1), 137-148 (2019)

Kraus, M. A., Pauli, A.: Konstitutive Modellierung der Bruchfragmente thermisch vorgespannter Gläser innerhalb der Plastizitätstheorie - Experiment und Numerik, Glasbau 2021, Ernst und Sohn Verlag (2021)

Labuz, J.F., Zang, A.: Mohr-Coulomb failure criterion. Rock Mech. Rock Eng. 45(6), 975-979 (2012)

Lang, H., Huder, J., Amann, P., Puzrin, A.M.: Bodenmechanik und Grundbau: Das Verhalten von Böden und Fels und die wichtigsten grundbaulichen Konzepte. Springer, Berlin (2010) 
Mang, H.A., Hofstetter, G.: Festigkeitslehre. Springer, Berlin (2000)

Mantari, J.L., Canales, F.G.: Finite element formulation of laminated beams with capability to model the thickness expansion. Compos. Part B Eng. 101, 107-115 (2016)

Miller, T.W., Cheatham Jr, J.B.: A new yield condition and hardening rule for rocks. In: International Journal of Rock Mechanics and Mining Sciences \& Geomechanics Abstracts, vol. 9, pp. 453-474. Elsevier, Amsterdam (1972)

Mohr, O.: Welche umstände bedingen die elastizitätsgrenze und den bruch eines materials. Z. Ver. Dtsch. Ing. 46(15241530), 1572-1577 (1900)

Möller, G.: Geotechnik: Bodenmechanik. Wiley, New York (2013)

Müllerschön, H.: Spannungs-verformungsverhalten granularer materialien am beispiel von berliner sand (2000)

Pelfrene, J.: Numerical analysis of the post-fracture response of laminated glass under impact and blast loading. Ph.D. thesis, Ghent University (2016)

Pelfrene, J., Van Dam, S., Van Paepegem, W.: Numerical analysis of the peel test for characterisation of interfacial debonding in laminated glass. Int. J. Adhes. Adhes. 62, 146-153 (2015)

Pour-Moghaddam, N.: On the Fracture Behaviour and the Fracture Pattern Morphology of Tempered Soda-Lime Glass, vol. 54. Springer, Berlin (2019)

Pour-Moghaddam, N.: Prediction of 2D macro-scale fragmentation of tempered glass. In: On the Fracture Behaviour and the Fracture Pattern Morphology of Tempered Soda-Lime Glass, pp. 121-181. Springer, Berlin (2020)

Rutter, E.H., Glover, C.T.: The deformation of porous sandstones; are Byerlee friction and the critical state line equivalent? J. Struct. Geol. 44, 129-140 (2012)

Sandler, I.S., Dimaggio, F.L., Baladi, G.Y.: Generalized cap model for geological materials. J. Geotech. Geoenvironmental Eng 102(ASCE\# 12243 Proceeding) (1976)

Senseny, P.E., Fossum, A.F., Pfeifle, T.W.: Non-associative constitutive laws for low porosity rocks. Int. J. Numer. Anal. Methods Geomech. 7(1), 101-115 (1983)
Seshadri, M.: Mechanics of glass-polymer laminates using multi length scale cohesive zone models. Ph.D. thesis (2001)

Smoltczyk, U.: Grundbau-Taschenbuch, Teil 1: Geotechnische Grundlagen, vol. 1. Wiley, New York (2001)

Spencer, A.J.M.: Continuum mechanics. Courier Corporation (2004)

Speranzini, E., Agnetti, S.: Strengthening of glass beams with steel reinforced polymer (SRP). Compos. Part B Eng. 67, 280-289 (2014)

Teotia, M., Soni, R.K.: Applications of finite element modelling in failure analysis of laminated glass composites: a review. Eng. Fail. Anal. 94, 412-437 (2018)

Timmel, M., Kolling, S., Osterrieder, P., Du Bois, P.A.: A finite element model for impact simulation with laminated glass. Int. J. Impact Eng 34(8), 1465-1478 (2007)

Vedrtnam, A., Pawar, S.J.: Laminated plate theories and fracture of laminated glass plate-a review. Eng. Fract. Mech. 186, 316-330 (2017)

Vernik, L., Zoback, M.D.: Estimation of maximum horizontal principal stress magnitude from stress-induced well bore breakouts in the Cajon pass scientific research borehole. J. Geophys. Res. Solid Earth 97(B4), 5109-5119 (1992)

Witt, K.J.: Grundbau-Taschenbuch: Teil 1: Geotechnische Grundlagen, vol. 1. Wiley, New York (2008)

Zienkiewicz, O.C., Valliappan, S., King, I.P.: Elasto-plastic solutions of engineering problems 'initial stress', finite element approach. Int. J. Numer. Methods Eng. 1(1), 75-100 (1969)

Zou, Y., Boley, C.: Eigenschaften und klassifikation von böden. In: Handbuch Geotechnik, pp. 13-60. Vieweg Teubner Verlag (2012)

Publisher's Note Springer Nature remains neutral with regard to jurisdictional claims in published maps and institutional affiliations. 